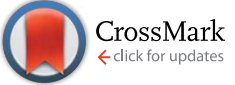

Cite this: RSC Adv., 2014, 4, 33785

Received 19th May 2014 Accepted 24th July 2014

DOI: $10.1039 / c 4 r a 04701 j$

www.rsc.org/advances

\title{
Ruthenium complexes as precursors for chemical vapor-deposition (CVD)
}

\author{
Ruchi Gaur $\uparrow^{\mathrm{a}}$ Lallan Mishra, $^{* a}$ M. Aslam Siddiqi ${ }^{\mathrm{b}}$ and Burak Atakan*b
}

Ruthenium and its compounds are often used as thin films and can be deposited by chemical vapor deposition. The quality of the films strongly depends on the inorganic precursors, their evaporation behaviour and thermochemistry. This is an area where different aspects of inorganic chemistry and chemical engineering must fit together to provide good thin films. It was noticed that providing firsthand information in one place especially for a learner of this area of research, and collection of reports on different types of ruthenium complexes as CVD precursors would be timely. Thus, in this review a bird's eye view of ruthenium complexes suitable for CVD technology, together with the presentation of different precursors, their synthesis, evaporation, decomposition and film formation is presented. A brief summary of the CVD technique is also presented with future-design, synthesis and usefulness of CVD precursors.

\section{Introduction}

Over the past few decades, there is a continuous advancement in the design and synthesis of new materials with enhanced functionalities for eventual application in devices for microelectronics and optoelectronics. Despite this progress, it continues to be difficult and challenging among material

${ }^{a}$ Department of Chemistry, Faculty of Science, Banaras Hindu University, Varanasi-221005, India.E-mail: Imishrabhu@yahoo.co.in

${ }^{b}$ Thermodynamics, IVG, Faculty of Engineering, and CeNIDE, University of Duisburg Essen, Lotharstr. 1, 47057 Duisburg, Germany. E-mail: aslam.siddiqi@uni-due.de; burak.atakan@uni-due.de

$\dagger$ Current address: Department of Chemistry, Indian Institute of Technology, Kanpur-208016, India, E-mail: ruchiuno@gmail.com. scientists to design selective and highly efficient new materials for thin film technology especially in microelectronic applications. The unique chemical and physical properties of ruthenium trigger a variety of applications in thin film technology, ${ }^{1}$ alkane hydrogenolysis, ${ }^{2}$ surface science, ${ }^{3}$ hydrogenation reactions, ${ }^{4}$ and Fischer-Tropsch reactions. ${ }^{5}$ It is well known that elemental ruthenium is found to be a very promising candidate in thin film technology because of its high work function $(4.7 \mathrm{eV})$, thermal stability even at higher temperature $\left(\sim 800^{\circ} \mathrm{C}\right)$, low bulk resistivity $(7 \mu \Omega \mathrm{cm})$ and low specific electrical resistivity even in its oxidized state. ${ }^{6}$ In particular, ruthenium has been shown to force $\mathrm{TiO}_{2}$ films grown on it into the high- $k$ rutile phase, making it attractive for capacitors in microelectronics applications. ${ }^{7}$ Ruthenium and its conducting

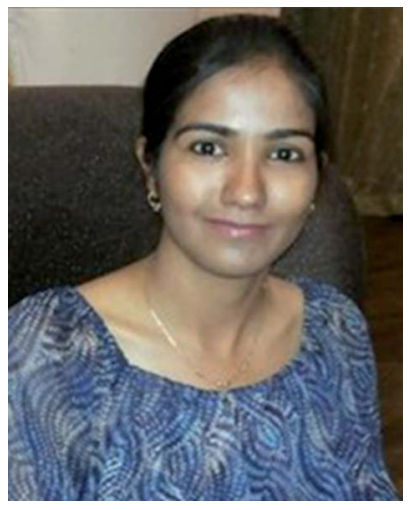

Ruchi Gaur received her B.Sc. and M.Sc. degrees from Chhatrapati Shahu Ji Maharaj University, Kanpur India. She obtained her Ph.D. (2012) from Banaras Hindu University, India, under the guidance of Prof. Lallan Mishra. Currently, she is working as a post doctoral fellow at the Indian Institute of Technology, Kanpur, India. Her research focuses on the area of metal based antitumor complexes, coordination-driven self assembly, and metal-organic frameworks.

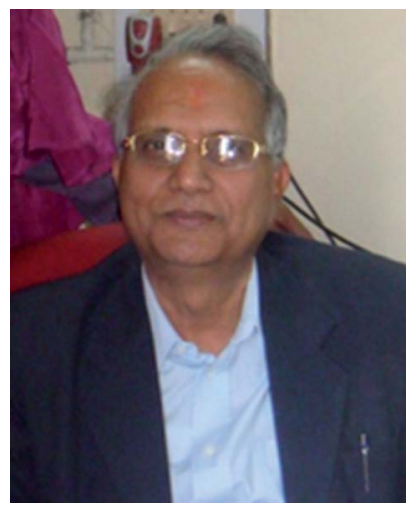

Prof. Lallan Mishra obtained his Ph.D. from D. D. U. Gorakhpur University, India. He did his post-doctoral work at IISc. Bangalore, I.I.T. Kanpur and University of Antwerp, Belgium. He joined the Department of Chemistry, Banaras Hindu University, Varanasi in 1989 and is presently working as Head of the department of $B H U$. His research interests are in the area of bioinorganic, supramolecular, development of metal based anti cancer drugs and coordination chemistry with the focus on architectural aspects, functional materials. 
thermodynamically stable oxide phase $\left(\mathrm{RuO}_{2}\right)$ have been used as metallic contact to high dielectric materials such as strontium titanate $\left(\mathrm{SrTiO}_{3}\right)$, barium strontium titanate $\left[(\mathrm{Ba}, \mathrm{Sr}) \mathrm{TiO}_{3}\right]{ }^{8}$ tantalum pentaoxide $\left(\mathrm{Ta}_{2} \mathrm{O}_{5}\right)^{9}$ and lead zirconate titanate $\left[\mathrm{Pb}(\mathrm{Zr}, \mathrm{Ti}) \mathrm{O}_{3}, \mathrm{PZT}\right]^{10}$ and may be used for the preparation of the next-generation gigabit-scale dynamic random access memories (DRAMS). ${ }^{\mathbf{1 1}, \mathbf{1 2}}$ Ruthenium thin films are also advantageous diffusion barrier as compared to over TaN based on diffusion barriers owing to its low resistivity, chemical stability and low solubility in $\mathrm{Cu}$ and thus they become a possible alternative for thin film technology. ${ }^{13}$ Ruthenium thin films have also been used as seed and barrier layers for copper and silicon deposition due to its high conductivity and chemical inactivity with copper and silicon. ${ }^{\mathbf{1 4}}$

Ruthenium is a promising candidate for developing a deeper understanding of chemical vapor deposition and precursor design for catalytic films due to much individual molecular behavior in surface science and catalysis. In early stage, ruthenium films were prepared by different techniques such as reactive sputtering, ${ }^{15}$ physical vapor deposition, ${ }^{\mathbf{1 6}}$ spray pyrolysis ${ }^{17}$ pulsed laser deposition (PLD) ${ }^{18}$ molecular-beam epitaxy (MBE) ${ }^{19}$ cathodic electrosynthesis ${ }^{20}$ and by a sol-gel process. ${ }^{21}$ But these alternative processes create problems such as low conformal coverage, poor crystallinity, high stress levels etc. in the thin films obtained. To overcome these problems the chemical vapor deposition (CVD) method is promising. It often offers excellent coverage, relatively soft conditions, and a compatibility for large scale processing. ${ }^{22}$ Ruthenium chemical vapor deposition and precursor design is of particular interest because of the outstanding film properties ${ }^{23}$ such as low resistivity, high thermal stability, good etching ability, good barrier properties against oxygen diffusion, high resistance against capacitor shorting due to the formation of hillocks, severe polarization fatigue and aging and so are useful in electronic applications. $^{24}$ Ruthenium is also a suitable substrate for growing periodically rippled graphene, ${ }^{25-27}$ which is attracting

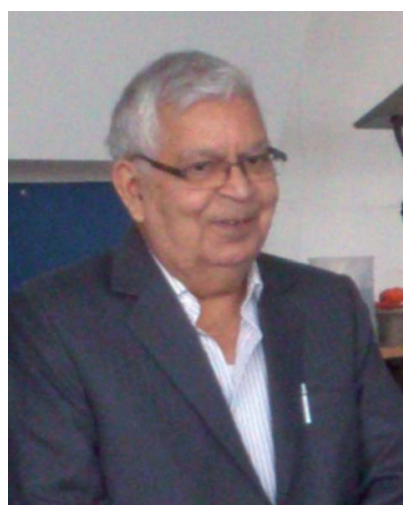

Dr M. Aslam Siddiqi received his Ph.D. from Lucknow University, Lucknow, India in 1972. Until his retirement in 2013 he was working as a senior scientist at the University of Duisburg-Essen (Germany) at the department of Thermodynamics. His main research fields are the thermodynamic properties of metalorganic compounds, vapor liquid equilibria and the fluid dependence of thermodynamic cycles for energy conversion. great interest for its periodically inhomogeneous electronic properties. ${ }^{28}$ One of the current frontiers is growing graphene on $\mathrm{Ru}$ thin films on sapphire and $\mathrm{SiO}_{2},{ }^{29-31}$ which is to date problematic for the low crystalline quality of $\mathrm{Ru}$ films on insulator substrates. The realization of this goal would allow exotic applications of graphene as a curved mirror for He-atom microscopy ${ }^{32,33}$ or for graphene/metal contacts in plasmonics. $^{34-36}$

Accordingly, there is still demand for ruthenium CVD source reagents as found better in view of their advantages such as suitability for scale-up synthetic operation, higher thermal and oxidative stability during storage, higher volatility upon heating, and the capability to induce facile metal deposition under designated CVD conditions. In this account, we have discussed the chemical vapor deposition technology of ruthenium using different $\mathrm{Ru}$ containing complexes as precursors. To give a background, a brief summary of the CVD technique and its classifications are also presented with regard to future-design, synthesis and usefulness of CVD precursors.

\section{A brief introduction to CVD}

Chemical vapor deposition is a technique by which a material is synthesized as a thin film, by the reaction of vapor phase compounds containing the constituents of the film. ${ }^{37}$ The solids are grown as polycrystalline, epitaxial or amorphous films depending on the materials and reactor conditions. Thus, the occurrence of chemical reactions is an essential characteristic of the CVD method. The kinetics and transport processes depend on surface and gas phase chemical reactions, parameters such as temperature, pressure, input concentration and rate of flow of the reaction are crucial. The CVD process and its reactor are selected by the requirements for substrate material, morphology and coating material, film thickness and uniformity, availability of precursors and cost. ${ }^{38}$ CVD can be carried out in cold-wall reactors or hot-wall reactors at typical

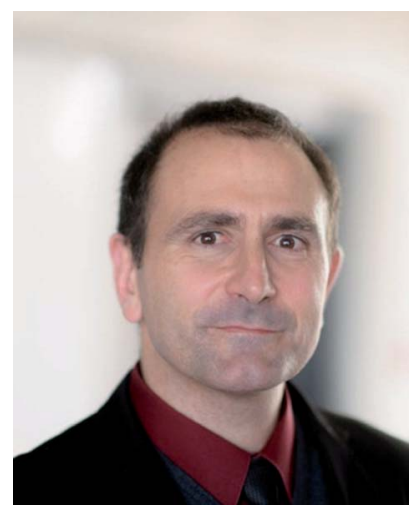

Prof. Dr Burak Atakan is the chair of thermodynamics in the faculty of engineering at the University of Duisburg-Essen (Germany) since 2002. He received his Ph.D. in physical chemistry at the University of Heidelberg (Germany) in 1992. After working as a scientist at the DLR (German Aerospace Research Center) in Stuttgart until 1995 he continued his research at the University of Bielefeld (Germany), where he obtained his habilitation in physical chemistry in 2000. His research fields are thermodynamic and transport properties of metalorganic compounds, chemical vapor deposition and chemical vapor infiltration of various compounds, energy conversion processes and combustion mechanisms. 
temperature ranging from $200-1600{ }^{\circ} \mathrm{C}$ and often at belowatmospheric pressures with and without carrier gases. ${ }^{39} \mathrm{~A}$ variety of enhanced CVD processes are established which involve the use of plasma, ions ${ }^{40}$ photons (also using lasers) hot filaments, or combustion reactions ${ }^{38}$ to increase deposition rates and/or lower deposition temperatures. Direct analytical techniques applied to CVD studies are Raman spectroscopy, absorption spectroscopy and gas chromatography. ${ }^{41}$ Qualitative and quantitative analysis of vapor phase could be carried out by direct attachment of a mass spectrometer to a CVD reactor. ${ }^{42,43}$

The principle of CVD process can be understood stepwise as:

(1) Precursors are transported in the gas phase, gas phase reactions can take place;

(2) Adsorption and transport of the precursors on the surface take place;

(3) Supply of energy (thermal, plasma, light) for breaking the precursor molecules and film formation;

(4) Transport on and desorption of the byproducts from the surface;

(5) Gas phase transport and evacuation of by-products in the gas-phase. ${ }^{44}$

Most often the reaction conditions are chosen in such a way that surface reaction is rate determining or limiting step, which is at relatively low temperatures or at higher temperatures. Chemical vapor deposition can occur in two different mechanistic ways: either the precursor species polymerize or react in the gas phase forming reactive gaseous species and then adsorb to the surface and form a thin film or the precursor species adsorb first on the surface and react then on the substrate. The first mechanism generally creates poorer coating adhesion compared to the second one. ${ }^{45}$

Thermodynamics predicts the feasibility of CVD process to occur under certain parameters and it can provide both qualitative and quantitative information about the process. Thus, one of the first steps in considering a CVD process is to perform the thermodynamical calculations to explore the general conditions required for the process to occur. Although, not always data for the free energy of formation of all vapors and condensed constituents of the system are available. Details regarding the thermodynamics of CVD can be found in an interesting review article by Kern and Ban. ${ }^{46,47}$

Besides thermodynamics, the kinetics of the deposition process is as important. The nature of the rate-controlling step changes with temperature and can often be determined from an Arrhenius plot. It suggests that at lower temperatures the ratecontrolling step is some surface process with a constant rate varying with $k=A \mathrm{e}^{-\Delta E / R T}, A$ is frequency factor, $\Delta E$ is the activation energy-usually varies from $25-100 \mathrm{kcal} \mathrm{mol}^{-1}$ for surface processes. At higher temperatures, the rate-controlling step is generally the transport either by diffusion or convection of the reactants to the reacting surface. The temperature dependence of gas phase diffusion is mild and the deposition-rate follows a less steep slope. At even higher temperatures the precursor may react to particles and a decrease in growth rate at very high temperatures is observed..$^{48}$ For example, a steep dependence of the deposition rate is observed at lower temperatures where as a milder dependence is observed at higher temperatures in deposition of Si from various sources ${ }^{49}$ The deposition-rate can also depend on the crystallographic orientation of the substrate as the deposition rate of GaAs is three to four times faster on the (111) surface of the substrate as compared to growth on the (100) surface..$^{50}$ The effect of dopants on the semiconductor growth rate and existence of meta-stable phases could also be considered as kinetic effects. ${ }^{51}$

The substrate temperature, pressure and reaction gas flow rates determine the film formation mechanism and this may help to improve the knowledge about the rate limiting factor which controls the nucleation or growth rate (kinetics). In the context of the present topic, Ru shall be regarded: Substrates like $\mathrm{SiO}_{2} / \mathrm{Si}$ were used mainly for pure Ru films deposition because of slow deposition rates on other substrates. ${ }^{52}$

Hones et al. established the growth kinetic of thin ruthenium oxide films from $\left[\mathrm{Ru}(\mathrm{tfa})_{3}\right]$ in a mixture of oxygen and water which follows a unimolecular reaction of the LangmuirHinshelwood-type. The reaction pathways of precursor molecule fragmentation is depicted in Fig. $1 .^{53}$ From the growth kinetics of $\left[\mathrm{Ru}(\mathrm{tfa})_{3}\right]$, it is concluded that

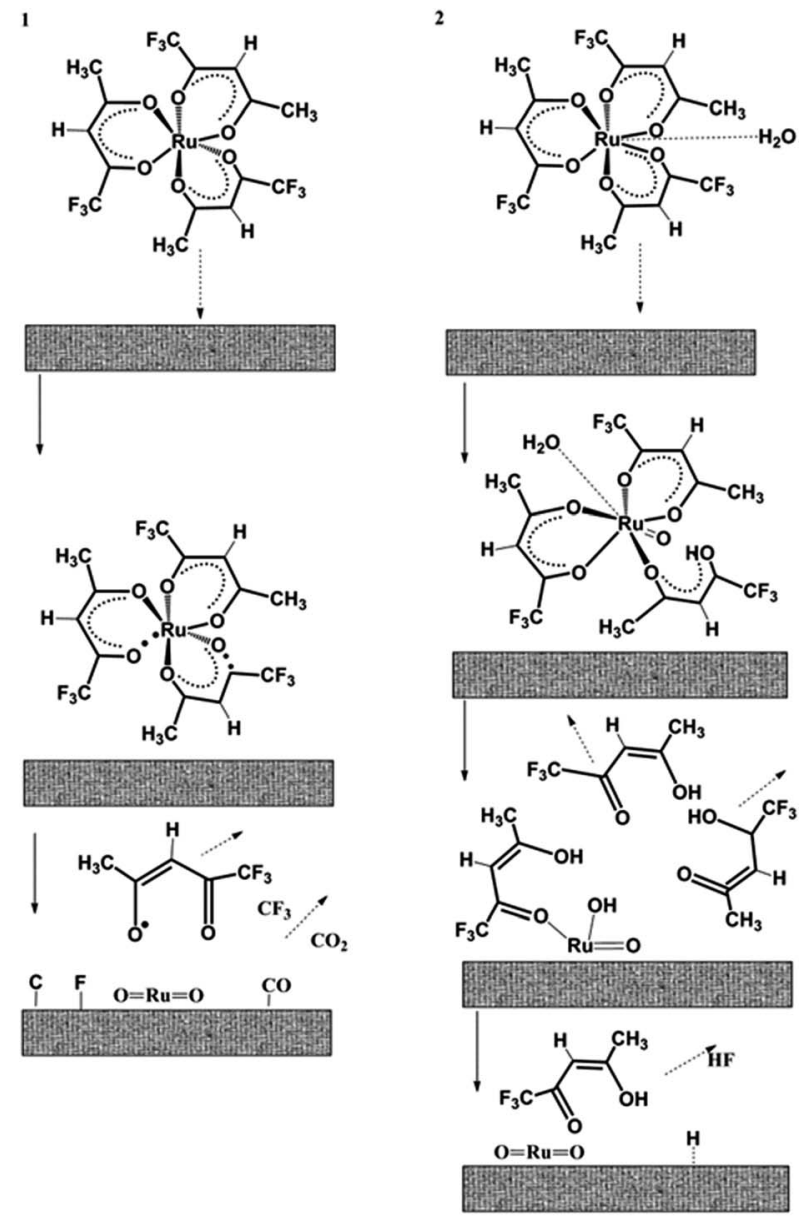

Fig. 1 Reaction mechanism of the $\left[\mathrm{Ru}(\mathrm{tfa})_{3}\right]$ precursor molecule at the substrate surface. (1) Thermolysis with formation of highly reactive radicals, without water. (2) Volatile reaction by-products formation by protonation of the ligands in the presence of water. Adapted from ref. 53. 
(1) $\left[\mathrm{Ru}(\mathrm{tfa})_{3}\right]$ provides most of the oxygen in the $\mathrm{RuO}_{2}$ film and the reaction is unimolecular.

(2) The growth rate varies exponentially with the temperature of the substrate. However, the growth rate of the film increases with the lowering of the partial pressure and it gets saturated at high partial pressures. This behaviour indicates that the reaction kinetics follows a Langmuir adsorption isotherm.

(3) For the deposition of ruthenium thin films, water vapor is required, because water molecules destabilize the precursor complex by partial protonation of the ligands.

As some substrates cannot withstand high temperatures, the use of a plasma or laser light may be a way to start chemical reactions at moderate temperatures. Also, CVD can be performed at different pressures. Many of these CVD variations were named separately as atmospheric pressure CVD (APCVD $)^{54}$ or low pressure CVD (LPCVD). ${ }^{55}$ Similarly ultrahigh vacuum CVD (UHVCVD) ${ }^{56}$ is sometimes used, then the process takes place below $\sim 10^{-8}$ mbar. Whereas, according to the activation used (by either thermally or plasma, laser light or hot wires or flames or others.), ${ }^{57,58}$ the processes are named as (c) plasmaenhanced CVD (PECVD) and (d) remote plasma-enhanced CVD (RPECVD) as well as (e) microwave plasma assisted CVD (MPCVD) (f) flame enhanced CVD. ${ }^{59}$ Alternatively, some further CVD processes are named such as (g) atomic layer CVD in which successive layer of different substances deposits and produce the layered crystalline film, (h) combustion CVD is mainly for nanomaterials and based on flame-based technique (i) metalorganic CVD (MOCVD) is the interesting class to deposit the thin films of metal or their oxides, the present review will mainly focus on the latter. Several other classes of CVD processes are described in the literature. ${ }^{45,60}$

The most common use of CVD is the manufacturing of conformal thin films. A variety of applications for such films play a crucial role in the production of integrated circuits (ICs), ${ }^{61}$ photovoltaic devices, ${ }^{62}$ high temperature resistant, corrosion-resistant and wear-resistant protective coating $s^{63}$ and formation of optical fibers, ${ }^{64}$ synthetic diamond etc. ${ }^{37}$ CVD is also used in the fabricating of optical storage media and is suitable for manufacturing semiconductor devices. ${ }^{65}$ These materials together with some optoelectronic materials like solid state diode lasers have revolutionized the communication technology and are obtained using CVD technique.

In this context, it is of worth to mention that even the optical component of the communications network, the fiberoptic cables are manufactured by CVD in order to achieve the desired refractive index profile. ${ }^{66}$ The highly bright blue and green light emitting devices (LEDs) based on group-III nitride alloys, like InGaN, are grown on sapphire substrates also formed by CVD technology.$^{67} \mathrm{CVD}$ plays a crucial role in the production of micro electro-mechanical structures (MEMS) which is mainly derived from the silicon microelectronics technology. Most MEMS devices are fabricated from polycrystalline silicon (polysilicon) films deposited on silicon wafers, with intermediate sacrificial $\mathrm{SiO}_{2}$ layers that are later removed by chemical etching. ${ }^{68}$

Most of the properties, like magnetic, optical and electrical properties of a particular composition of a CVD film depends on its structure. Therefore, factors controlling the structure are of importance. Nucleation and formation of polycrystalline, amorphous and epitaxial CVD films is briefly discussed here. Older concepts of nucleation are based on a thermodynamical approach whereas newer concept of atomistic nucleation are based on statistical mechanics taking into account the chemical bonding characteristics of the solid surface. Different solid surfaces do not have equal bonding characteristics. Those with stronger bonding characteristics favour nucleation. ${ }^{69}$ The growing nuclei then come into contact and finally coalesce, forming a continuous film. After reaching a certain size, nuclei become energetically more favourable and growth dominates re-evaporation. ${ }^{70}$

Regular, oriented growth of a polycrystalline substance on another one, is called epitaxy. Epitaxial growth is often a desirable feature in CVD films, mainly in microelectronics, as such films are found superior with regard to their very well ordered and smooth surfaces compared to both, polycrystalline and amorphous films, respectively. ${ }^{71}$ However, for many applications, polycrystalline or amorphous films are sufficient. These structural forms are more common in CVD as epitaxial films can only be obtained under specific condition like good lattice match between film and substrate, in a certain temperature range and at proper reactant concentrations. In the absence of these conditions, polycrystalline or amorphous modifications of the same material are obtained. The CVD technique has also been found useful in making films of insulating and semiconducting materials which have a wide range of applications specially in modern microelectronic technology and protective coating for high-temperature materials. However, most of the metal films including ruthenium follow a 3D, Vollmer-Weber growth mechanism owing to their high surface energy; this leads to the growth of polycrystalline, columnar films by CVD. ${ }^{72-74}$

\section{Desirable properties of CVD precursors}

Primarily, thin film formation by CVD requires that the precursor should be highly volatile, ${ }^{75}$ soluble in inert solvents if spray evaporation is intended, as inert solvents prevent their own reactions with the precursors and they should be thermally stable at vaporization temperatures, so that no decomposition occurs during vaporization. Furthermore, they should have a preferential reactivity towards the substrate and the growing film. Other factors which determine the structure of the deposited film, are the ratio of deposition rate to surface diffusion rate (time available for surface processes) and the ratio of power density to deposition rate. ${ }^{76,77}$ The exposed precursor surface area is another important factor which irrespective of the volume (if other factors are constant) determines the rate of vaporisation. The deposition of clean thin films, depends on the decomposition mechanism of the precursor, the temperature regime, but also upon the carrier gas used in the reactor. ${ }^{78}$ With respect to ruthenium it is found that CVD experiments conducted under high $\mathrm{O}_{2}$ concentrations lead to the formation of rutile phase $\mathrm{RuO}_{2}$ through in situ metal 
oxidation. ${ }^{79,80}$ It is also believed that higher oxidation states may have a higher activation energy barrier which may induce hindrance for metal reduction in situ and its deposition. This can also account for the greater stability of the source precursor ${ }^{78}$ Under inert gas flow the mass loss of the precursor out of a crucible with time is nearly linear (for the exact theory, see ref. 81) and the residual mass should be negligible. ${ }^{\mathbf{1 1}}$

Since, the volatility is a key property of a CVD precursor it is interesting to enumerate the factors which decrease the vapor pressure in a series of comparable compounds, in order to get an idea of how good (or unsuitable) precursors may look like. Charged or highly polar species are in general non volatile. Adduct formation, polymerization and H-bonding also tend to reduce volatility. Thus, for maximum volatility, molecule must be designed so that steric and inductive effects minimize its tendency of adduct or polymer formation. In this context, metal complexes containing $\beta$-diketones are usually found to be volatile. Substitution of $\mathrm{H}$ by $\mathrm{F}$ is found to increase the volatility of the corresponding complexes further. The increase in volatility of fluorine containing $\beta$-diketonates corresponds directly to the extent of fluorine substitution. This owes to increased electronegativity of fluorine atoms as dominating the outer periphery of the complex. The fluorocarbon shell then reduces the van der Waals forces and intermolecular hydrogen bonding between fluorine substituted $\beta$-diketonates. For example, introduction of $\mathrm{CF}_{3}$ groups into the pyrazole moiety increases the volatility of bridged ruthenium complexes as compared to nonfluorinated analogues. This is due to the repulsive force between lone electron pairs of the fluorine atoms and the low polarizability of the C-F bonds. ${ }^{82,83}$ A detailed account of the effect of the nature of metal ions and ligand frameworks on the volatility of metal $\beta$-diketonates had already been presented in earlier review. ${ }^{\mathbf{8 4}, \mathbf{8 5}}$

\section{Different classes of ruthenium complexes used as CVD precursors}

Since precursors are so important in CVD, we would like to go through the different classes of ruthenium precursors aiming to summarize the state of the art and in order to identify potentials for design and development of precursors. Often precursors are synthesized to be applied in microelectronics and optoelectronics aiming to reduce the thermal budget of film formation. The ruthenium precursors stem either from the available classes of metal complexes or they are even specially engineered compounds. In the deposition process, the Ru-adsorbate bonds play an important role. Initially, CVD precursors included only metallic ruthenium as well as ruthenium dioxide $\mathrm{RuO}_{2} \cdot{ }^{86} \mathrm{High}$ quality $\mathrm{RuO}_{2}$ thin film can be obtained by a simple decomposition approach of the volatile precursor $\mathrm{RuO}_{4}$ at $150-220^{\circ} \mathrm{C}$ on either glass or silicon substrates $\mathrm{RuO}_{4} \rightarrow \mathrm{RuO}_{2}+\mathrm{O}_{2}$ by lowtemperature chemical vapor deposition; the films are found to be free of carbon impurities, which is not surprising regarding the carbon free precursors.

Later on, Sankar et al. prepared crystalline thin film of ruthenium and $\mathrm{RuO}_{2}$ on polyurethane or poly(methyl methacrylate) polymers. Amorphous thin films were deposited on polystyrene or poly(ether/ester)polyurethane block copolymers from volatile $\mathrm{RuO}_{4}$ in presence of $\mathrm{H}_{2}$ carrier gas. ${ }^{24}$ They choose $\mathrm{RuO}_{4}$ as precursor owing to well established fixative stain of saturated/unsaturated polymers by TEM studies. It developed a direct reaction with unsaturated sites $n$ or with $\mathrm{C}-\mathrm{H}$ bonds on the polymers with reduction of ruthenium. The films were characterized by different techniques such as Auger, XPS, XANES, XRD and SEM. However recently a large number of ruthenium complexes like ruthenium alkoxides, ruthenium alkyls, ruthenium amidinates, ruthenium diketonates, ruthenium carbonyls and others were exploited as precursor complexes. ${ }^{1,53,81-84}$ Thus, it is interesting to classify such complexes in terms of the nature of bonding of organic ligands formed by ruthenium and is described as follows:

\section{(a) Ruthenium carbonyls, diketonates and their derivatives}

Before the development of metal-organic precursors, ruthenium pentacarbonyl $\left[\mathrm{Ru}(\mathrm{CO})_{5}\right] \mathbf{1}$ and triruthenium dodecacarbonyl $\left[\mathrm{Ru}_{3}(\mathrm{CO})_{12}\right] 2$ were exploited as CVD precursors. ${ }^{87}$ The molecular structures of some important ruthenium carbonyls are depicted in Fig. 2. Generally, mononuclear ruthenium carbonyls like ruthenium pentacarbonyl, $\mathrm{Ru}(\mathrm{CO})_{5}$ with a vapor pressure of $50 \mathrm{~mm} \mathrm{Hg}$ at $18{ }^{\circ} \mathrm{C}$ starts to decompose at $-18{ }^{\circ} \mathrm{C}$. This characteristic was used by Berry et $a .^{88}$ and was successfully exploited to grow thin films by using ruthenium pentacarbonyl $\left[\mathrm{Ru}(\mathrm{CO})_{5}\right]$. The compound showed limited commercial use as CVD precursor due to its low stability. The decomposition of $\mathrm{Ru}(\mathrm{CO})_{2} \mathrm{Cl}_{2}$ or $\mathrm{Ru}(\mathrm{CO}) \mathrm{Br}$ in the absence of air at $200{ }^{\circ} \mathrm{C}$ leads to the formation of bright metallic ruthenium films. However, ruthenium thin films were also prepared by annealing of

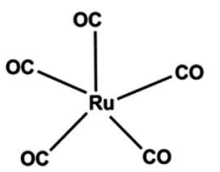

1

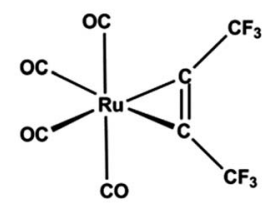

3

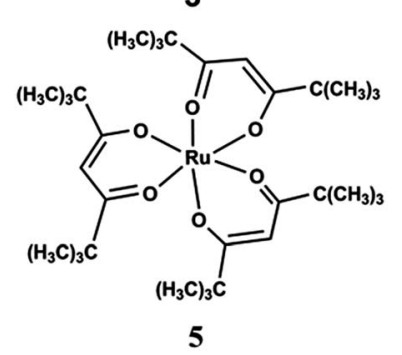

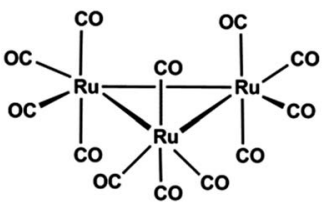

2

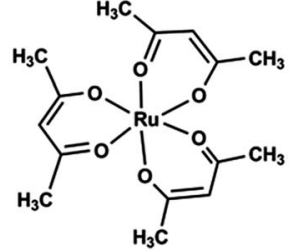

4

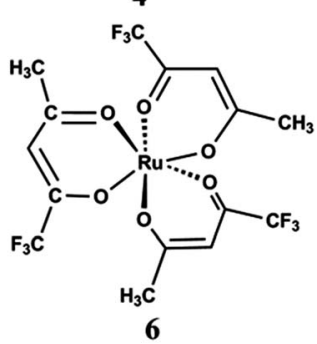

Fig. 2 Structures of ruthenium carbonyl derivatives. 
$\mathrm{Ru}(\mathrm{CO})_{2} \mathrm{Br}$ (boiling point $118^{\circ} \mathrm{C}$, subl. m. p. $140{ }^{\circ} \mathrm{C}$ ) or $\mathrm{Ru}(\mathrm{CO})_{3} \mathrm{I}$ (boiling point $114{ }^{\circ} \mathrm{C}$, subl. m.p. $120^{\circ} \mathrm{C}$ ) in a stream of oxygen and phosgene. A pure ruthenium film was also prepared at $595{ }^{\circ} \mathrm{C}$ in a hydrogen atmosphere. ${ }^{89}$

In 2004, Wang et al. reported pure and uniform Ru films on Ta and low-resistivity films on $\mathrm{SiO}_{2}$, they were grown by thermal CVD at temperatures as low as $423 \mathrm{~K}\left(150{ }^{\circ} \mathrm{C}\right)$ using $\mathrm{Ru}_{3}(\mathrm{CO})_{12} 2$ without accompanying reactive gas. ${ }^{90}$ Senzaki et al. ${ }^{91}$ reported a monometallic alkyne carbonyl ruthenium complex $\left[\mathrm{Ru}(\mathrm{hfb})(\mathrm{CO})_{4}\right]$ 3, where hfb $=$ hexafluoro-2-butyne which produced a film of $1800 \AA$ thickness in 3 min without any carrier gas at $500{ }^{\circ} \mathrm{C}$.

The second category of ruthenium precursor complexes are ruthenium- $\beta$-diketonates or $\mathrm{Ru}(\mathrm{CO})_{2}(\beta \text {-diketonates })_{2} \cdot{ }^{92}$ Simple complexes of type $\left[\mathrm{Ru}(\mathrm{acac})_{3}\right] \mathbf{4}$, acac $=$ acetylacetonatemonoanion (brown colour) were prepared by Wolf et al. ${ }^{93} \mathrm{~A}$ modified procedure by Rose et al. was also exploited to prepare ruthenium complexes. ${ }^{94}$ Its thermal properties for the preparation of $\mathrm{RuO}_{2}$ films by CVD was studied by Bykov et al..$^{95}$ (see also Table 1) The complex and its trifluorinated derivative were found as prospective precursors in CVD for the preparation of $\mathrm{RuO}_{2}$ and $\mathrm{Ru}$ films. ${ }^{96}$ The parent complex $\left[\mathrm{Ru}(\mathrm{acac})_{3}\right]$ follows similar decomposition pathway in both a nitrogen and a hydrogen containing atmosphere in TG measurements. ${ }^{97}$ Both the complexes melted at 232 and $216{ }^{\circ} \mathrm{C}$, respectively with a corresponding sublimation yield of 65.00 and $100.00 \%$. The thermodynamic properties of several $\beta$-diketone complexes have been widely covered in the literature. ${ }^{98}$

Green et al. also reported that ruthenium acetylacetonate resulted in the deposition of $\mathrm{RuO}_{2}$, only at elevated temperatures of $873 \mathrm{~K}$. These films proved to have excellent conformation, which is one of the main advantages of the CVD process. ${ }^{99}$ Conducting thin films of $\mathrm{RuO}_{2}$ were grown on glass by metalorganic chemical vapor deposition (MOCVD) at lower substrate temperatures i.e. $623 \mathrm{~K}$ from tris-trifluoroacetylacetonate-ruthenium $^{\text {III }}\left[\mathrm{Ru}(\mathrm{tfa})_{3}\right] 6$ tri substituted fluoro derivative of acetyl acetonate. $^{100}$

The study thus, indicated that $\left[\mathrm{Ru}(\mathrm{tfa})_{3}\right]$ is a good CVD precursor due to its high volatility and high thermal stability in both vacuum and in the presence of $\mathrm{O}_{2}$. Additionally, there are no transport problems of the compound to the substrate. The acceptable temperature regime for the deposition of $\mathrm{RuO}_{2}$ film by both precursors $\left[\mathrm{Ru}(\mathrm{acac})_{3}\right]$ and $\left[\mathrm{Ru}(\mathrm{tfa})_{3}\right]$ is $300^{\circ} \mathrm{C}$ or higher. A mixture of oxygen and water as carrier gas improved several thin film properties like resistivity. The thin film growth mechanism was studied by in situ ellipsometry ${ }^{53}$ which showed that the nucleation occurred with lateral and vertical island growth in a first step followed by a homogeneous film growth preserving the surface roughness. A model reaction mechanism is proposed for growth kinetics: The reaction kinetics follows a first-order Langmuir-Hinshelwood mechanism with growth rate dependent deposition parameters. ${ }^{101}$ The film properties such as conductivity and adhesion were improved in the presence of water vapor due to a destabilization of the precursor complex which catalyzes the fragmentation at the hot surface and stabilizes the volatile ligand.

Vasilyev et al. reported surface selective growth of ruthenium films from tricarbonyl $\left(\eta^{4}\right.$-cyclohexa-1,3-diene)ruthenium 7 under low-temperature pulsed CVD conditions in the temperature range of $110-275^{\circ} \mathrm{C}$ as shown in Fig. $3 .^{102}$ A year later, the Vasilyev group further investigated the resistivity and surface morphology of Ru films grown on sub-nanometer-thick Pt-Pd alloy seed layers in a surface selective growth region at $110-185{ }^{\circ} \mathrm{C}$ using tricarbonyl $\left\{\eta^{4}\right.$-cyclohexa-1,3-diene $\}$ ruthenium, ammonia, nitrous oxide, hydrogen, and pulsed chemical vapor deposition conditions. ${ }^{\mathbf{1 0 3}}$ The grown film morphology was stable up to $400-600{ }^{\circ} \mathrm{C}$ even after rapid thermal processing but revealed surface agglomeration at $700{ }^{\circ} \mathrm{C}$. Vasilyev ${ }^{\mathbf{1 0 4}}$ further studied the nucleation and initial stages of the growth of ruthenium layers on different surfaces in the temperature range 110-350 ${ }^{\circ} \mathrm{C}$ under the pulsed deposition from vapor phase with participation of a carbonyl-diene precursor $\left[\mathrm{Ru}(\mathrm{CO})_{3} \mathrm{C}_{6} \mathrm{H}_{8}\right]$ in the presence of $\mathrm{NH}_{3}, \mathrm{~N}_{2} \mathrm{O}$ and $\mathrm{H}_{2}$ as the second reagent. The growth of the ruthenium layers, formation of nuclei (nucleation) proceeds via a complex multifactor process which depends on the parameters of the deposition process, its type, properties and the uniformity of the sample surface. The Ru nucleation was determined at a stage of growth of the layers and is improved depending on the surface type at a low deposition temperature. It follows the order: $\mathrm{Si}_{3} \mathrm{~N}_{4} \leq \mathrm{SiO}_{2} ; \mathrm{Si}<\mathrm{Al}_{2} \mathrm{O}_{3} ; \mathrm{HfO}_{2}$ $\leq$ Pt-Pd; Pt; Ru.

In 2001, Lee et al. explored pure and highly conducting $\mathrm{RuO}_{2}$ thin films with good electrical resistivity as low as $45 \mu \Omega \mathrm{cm}$ using tris(2,2,6,6-tetramethyl-3,5-heptanedionato)ruthenium $\left[\mathrm{Ru}(\mathrm{tmhd})_{3}\right] \mathbf{8}$ as depicted in Fig. 6. The films were deposited only on $\mathrm{Si}$ substrates at $250-450{ }^{\circ} \mathrm{C}$ by low pressure metal organic chemical vapor deposition (LPMOCVD). ${ }^{\mathbf{1 0 5}}$ It is observed that $\left[\mathrm{Ru}(\mathrm{tmhd})_{3}\right]$ is a very promising CVD precursor due to its high vapor pressure and low decomposition temperature. As $\left[\mathrm{Ru}(\mathrm{tmhd})_{3}\right]$ is a solid substance, its direct delivery in the reactor creates some problem. So, Direct liquid injection (DLI) systems were used with a flash evaporator by dissolving $\left[\mathrm{Ru}(\mathrm{tmhd})_{3}\right]$ in

Table 1 Threshold Temperatures of thermolysis of $\mathrm{Ru}(\mathrm{acac})_{3}$ and $\mathrm{Ru}(\mathrm{tfa})_{3}$ source ref. 95

\begin{tabular}{|c|c|c|c|c|c|}
\hline Compound & Process & Number of points & $T /{ }^{\circ} \mathrm{C}$ & $\Delta H_{\mathrm{T}}^{\mathrm{o}} \mathrm{kJ} \mathrm{mol}^{-1}$ & $\Delta S_{\mathrm{T}}^{\mathrm{o}} \mathrm{kJ}(\mathrm{mol}$ \\
\hline $\begin{array}{l}\text { Flow methoc } \\
{\left[\mathrm{Ru}(\mathrm{acac})_{3}\right]}\end{array}$ & Subl. & 7 & $150-220$ & $127.0 \pm 0.9$ & $212.5 \pm 2.0$ \\
\hline \multicolumn{6}{|c|}{ Silica-membrane zero gauge } \\
\hline $\begin{array}{l}{\left[\mathrm{Ru}(\mathrm{tfa})_{3}\right]} \\
{\left[\mathrm{Ru}(\mathrm{tfa})_{3}\right]}\end{array}$ & $\begin{array}{l}\text { Subl. } \\
\text { Vapor }\end{array}$ & $\begin{array}{l}13 \\
11\end{array}$ & $\begin{array}{l}110-150 \\
160-210\end{array}$ & $\begin{array}{l}90.0 \pm 3.0 \\
78.7 \pm 0.8\end{array}$ & $\begin{array}{l}163.2 \pm 7.2 \\
137.2 \pm 1.7\end{array}$ \\
\hline
\end{tabular}




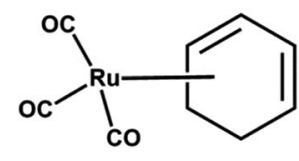

$\left[\mathrm{Ru}(\mathrm{CO})_{3} \mathrm{C}_{6} \mathrm{H}_{8}\right] 7$

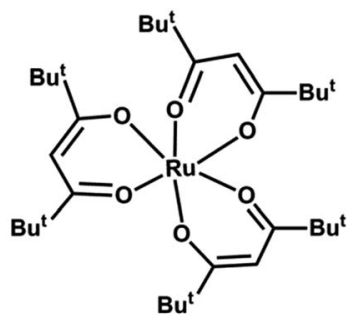

$\left[\mathrm{Ru}(\mathrm{tmhd})_{3}\right] 8$

Fig. 3 Molecular structure of tricarbonyl $\left(\eta^{4}\right.$-cyclohexa-1,3-diene) ruthenium and $\left[\mathrm{Ru}(\mathrm{tmhd})_{3}\right]$.

$n$-butylacetate. ${ }^{23}$ The ruthenium and ruthenium oxide thin films were deposited in a temperature range of $250-450{ }^{\circ} \mathrm{C}$. The formation of pure ruthenium thin films was preferred at low $\mathrm{O}_{2}$ flow rate $(300 \mathrm{sccm})$ and high injection rate $\left(0.07 \mathrm{~mL} \mathrm{~min}^{-1}\right)$ of the precursor solution over $350{ }^{\circ} \mathrm{C}$. However $\mathrm{RuO}_{2}$ films with low resistivity (approximately 45-60 $\mu \Omega$ ) were deposited at lower injection rate having dense and smooth surface morphology. Bai et al. also reported a highly conductive $\mathrm{RuO}_{2}$ thin films with either (110)- or (101)-textured orientations grown by metalorganic chemical vapor deposition (MOCVD) on both $\mathrm{SiO}_{2} /$ $\mathrm{Si}(001)$ and $\mathrm{Pt} / \mathrm{Ti} / \mathrm{SiO}_{2} / \mathrm{Si}(001)$ substrates from $\mathrm{Ru}(\mathrm{tmhd})_{3}$ at low temperature ranges from $275{ }^{\circ} \mathrm{C}$ to $425{ }^{\circ} \mathrm{C} .{ }^{106}$

Lee et al. again extended the work by developing and characterizing air stable ruthenium CVD precursors such as $\left[\mathrm{Ru}(\mathrm{CO})_{2}(\mathrm{hfac})_{2}\right] 9$ and $\left[\mathrm{Ru}(\mathrm{CO})_{2}(\mathrm{tmhd})_{2}\right] \mathbf{1 0}(\mathrm{hfac}=1,1,1,5,5,5-$ hexafluoro-2,4-pentanedione or hexafluoro acetyl acetonate, tmhd $=\operatorname{tris}(2,2,6,6$-tetramethyl-3,5-heptanedionato)) which showed deposition of pure $\mathrm{Ru}$ films with small amounts of impurities in the presence of carrier gases such as $\mathrm{H}_{2}$ and $\mathrm{Ar}^{107}$ Based on the isolation and characterization of the volatile coproducts, they proposed the possible mechanism for Ru deposition. The only free ligand (tmhd) $\mathrm{H}$ and metallic $\mathrm{Ru}$ was obtained using $\left[\mathrm{Ru}(\mathrm{CO})_{2}(\mathrm{tmhd})_{2}\right] \mathbf{1 0}$ as the source reagent in $\mathrm{H}_{2}$ as the carrier gas. However in the case of $\left[\mathrm{Ru}(\mathrm{CO})_{2}(\mathrm{hfac})_{2}\right] \mathbf{9}$, free ligand (hfac) $\mathrm{H}$ together with a dark red $\mathrm{Ru}(\mathrm{III})$ complex, [Ru(hfac)3] $(25 \pm 41 \%)$ were obtained. The outline of the deposition pathway is depicted in Scheme 1.

Further, Lai et al. ${ }^{108}$ synthesized diketonate complexes of ruthenium such as $\left[\mathrm{Ru}(\mathrm{CO})_{2}(\mathrm{hfac})_{2}\right] \mathbf{9},\left[\mathrm{Ru}(\mathrm{CO})_{2}(\mathrm{tmhd})_{2}\right] \mathbf{1 0}$, $\left[\mathrm{Ru}(\mathrm{CO})_{2}(\mathrm{acac})_{2}\right] \mathbf{1 1}$ and $\left[\mathrm{Ru}(\mathrm{CO})_{2}(\mathrm{tfac})_{2}\right] 12$ in high yields by the reaction of $\mathrm{Ru}_{3}(\mathrm{CO})_{12}$ with substituted $\beta$-diketone ligands such as (hfac) $\mathrm{H}$, (tmhd) $\mathrm{H},(\mathrm{acac}) \mathrm{H}$ and (tfac) $\mathrm{H}$ at $160-170{ }^{\circ} \mathrm{C}$ in hydrocarbon solvents (pentane or hexane) as depicted in Scheme 3. One isomer of the tfac complex (12a) was also isolated during the reaction revealing octahedral coordination

$$
\begin{gathered}
{\left[\mathrm{Ru}(\mathrm{CO})_{2}(\text { thmd })_{2}\right]+\mathrm{H}_{2} \longrightarrow \mathrm{Ru}(\mathrm{s})+2 \mathrm{CO}+2 \text { (thmd)H }} \\
3\left[\mathrm{Ru}(\mathrm{CO})_{2}(\mathrm{hfac})_{2}\right]+\mathrm{H}_{2} \longrightarrow \mathrm{Ru}(\mathrm{s})+6 \mathrm{CO}+2\left[\mathrm{Ru}(\mathrm{hfac})_{3}\right]
\end{gathered}
$$

Scheme 1 Mechanism for the formation of ruthenium thin film from $\left[\mathrm{Ru}(\mathrm{CO})_{2}(\mathrm{hfac})_{2}\right]$ and $\left[\mathrm{Ru}(\mathrm{CO})_{2}(\mathrm{tmhd})_{2}\right]$. Adapted from ref. 91.

geometry with two CO ligands located at cis-positions and with $\mathrm{CF}_{3}$ groups of $\beta$-diketonate ligands trans to the $\mathrm{CO}$ ligands which was identified by a single crystal X-ray diffraction study. Thermogravimetric analysis (TGA) showed that complex 9 is more volatile than its parent acac complex $\mathbf{1 1}$ owing to the $\mathrm{CF}_{3}$ group reducing the intermolecular attraction. Whereas, complex 10 exhibited a lower volatility than complex $\mathbf{1 2}$ due to the smaller molecular weight which results in weaker van der Waals attractive interactions between each of the individual molecules. The deposition of ruthenium thin film was observed at temperatures of $350-450{ }^{\circ} \mathrm{C}$ under $\mathrm{H}_{2}$ atmosphere or at temperatures of $275{ }^{\circ} \mathrm{C}-400{ }^{\circ} \mathrm{C}$ using a $2 \%$ mixture of $\mathrm{O}_{2}$ in argon as carrier gas from complexes 9 and 10. Under $100 \% \mathrm{O}_{2}$ atmosphere, conductive $\mathrm{RuO}_{2}$ thin films were deposited at a preferred (200) orientation at $350{ }^{\circ} \mathrm{C}$ with the lowest resistivity $(156 \mu \Omega \mathrm{cm})$ obtained using complex 9 . The controlled partial pressure of oxygen (i.e. $2 \%$ ) and accurate tuning of the deposition temperature are important for the formation of pure thin films i.e. a higher partial pressure of $\mathrm{O}_{2}$ and higher temperatures would result in a mixture of $\mathrm{Ru}$ and $\mathrm{RuO}_{2}$ thin films. The synthetic strategy and molecular structures of some dicarbonyl $\beta$-diketonato ruthenium derivatives are shown in Fig. 4(A) and (B), respectively. Details of the different CVD parameters observed for these complexes under different conditions are summarized in Table 2 .

Cheng et al. ${ }^{109}$ investigated the initial growth behavior of ruthenium $(\mathrm{Ru})$ on $\mathrm{Si}(100)$ surfaces from $\left(\mathrm{Ru}(\mathrm{hfac})_{2}(\mathrm{CO})_{2}\right)$ in a temperature range of $548 \leq T \leq 623 \mathrm{~K}$ using atomic force microscopy and X-ray photoelectron spectroscopy. The Volmer-

\section{$\mathrm{Ru}_{3}(\mathrm{CO})_{12}+6$ (diketonate) $\mathrm{H} \longrightarrow 3\left[\mathrm{Ru}(\mathrm{CO})_{2}(\text { diketonate })_{2}\right]+3 \mathrm{H}_{2}+6 \mathrm{CO}$}

(A)

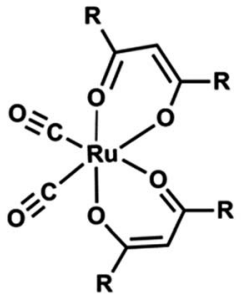

$\mathrm{R}=\mathrm{CF}_{\mathbf{3}} \mathbf{9}$

$R=t-B u 10$

$R=$ Me 11

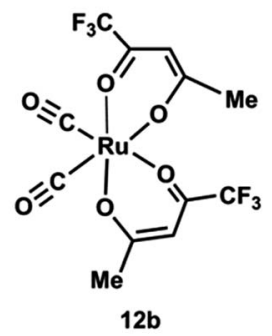

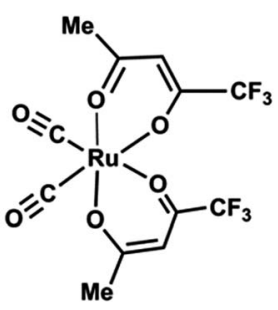

$12 \mathrm{a}$

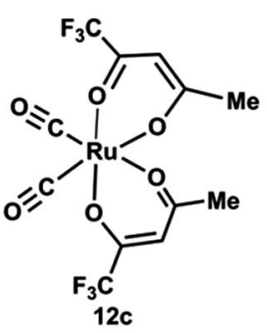

(B)
Fig. 4 (A) Schematic illustration of reaction of metal carbonyl with diketones (B) Some dicarbonyl $\beta$-diketonato ruthenium derivatives. Adapted from ref. 108. 
Table 2 Experimental data of CVD experiments. Source ref. $108^{a}$

\begin{tabular}{|c|c|c|c|c|c|c|c|c|}
\hline Entry & Source & CGFR/sccm & $T_{\mathrm{S}} /{ }^{\circ} \mathrm{C}$ & $T_{\mathrm{D}} /{ }^{\circ} \mathrm{C}$ & $P_{\mathrm{S}} /$ Torr & Thickness/Å & $\begin{array}{l}D \\
\text { rate/Å } \min ^{-1}\end{array}$ & $\begin{array}{l}\text { Resistivity } \\
\rho / \mu \Omega \mathrm{cm}\end{array}$ \\
\hline 1 & 9 & $\mathrm{H}_{2}(20)$ & 28 & 350 & 5 & 1600 & 23 & 618 \\
\hline 2 & 9 & $\mathrm{H}_{2}(20)$ & 28 & 400 & 5 & 3200 & 46 & 39 \\
\hline 3 & 9 & $\mathrm{H}_{2}(20)$ & 28 & 450 & 5 & 4800 & 69 & 26 \\
\hline 4 & 9 & $\mathrm{O}_{2}(2 \%) / \operatorname{Ar}(10)$ & 50 & 300 & 5 & 600 & 12 & 34 \\
\hline 5 & 9 & $\mathrm{O}_{2}(2 \%) / \operatorname{Ar}(10)$ & 50 & 350 & 5 & 1450 & 28 & 15 \\
\hline 6 & 9 & $\mathrm{O}_{2}(2 \%) / \mathrm{Ar}(10)$ & 50 & 400 & 5 & 5000 & 96 & 37 \\
\hline 7 & 10 & $\mathrm{O}_{2}(2 \%) / \mathrm{Ar}(10)$ & 80 & 275 & 1 & 1400 & 31 & 206 \\
\hline 8 & 10 & $\mathrm{O}_{2}(2 \%) / \mathrm{Ar}(10)$ & 80 & 325 & 1 & 1600 & 36 & 111 \\
\hline 9 & 10 & $\mathrm{O}_{2}(2 \%) / \operatorname{Ar}(10)$ & 80 & 375 & 1 & 3000 & 67 & 24 \\
\hline 10 & 9 & $\mathrm{O}_{2}(10)$ & 25 & 300 & 5 & 1600 & 80 & 218 \\
\hline 11 & 9 & $\mathrm{O}_{2}(10)$ & 25 & 350 & 5 & 4800 & 240 & 156 \\
\hline 12 & 9 & $\mathrm{O}_{2}(10)$ & 25 & 400 & 5 & 5400 & 270 & 170 \\
\hline
\end{tabular}

${ }^{a}$ CGFR: carrier gas flow rate, $T_{\mathrm{s}}$ : source temperature, $T_{\mathrm{D}}$ : deposition temperature, $P_{\mathrm{S}}$ : initial system pressure, $D$ rate: deposition rate. and Cont.: content of nonmetal elements determined by XPS.

Weber growth ${ }^{\mathbf{1 1 0}}$ dominates the initial stage of the deposition for the growing sample and the nucleation rate increases with increasing substrate surface termination sites. They also studied the kinetic behaviour of the nuclei formation process, which showed a lower activation energy on H-terminated surface $\left(5 \mathrm{kcal} \mathrm{mol}^{-1}\right)$ than on the oxide surface $\left(11 \mathrm{kcal} \mathrm{mol}^{-1}\right)$. The reaction kinetics suggest that the deposition is controlled by hfac dissociation step due to high dissociation energy for $\mathrm{Ru}-$ hfac (241 kcal mol${ }^{-1}$ ) compared to $\mathrm{Ru}-\mathrm{CO}\left(57 \mathrm{kcal} \mathrm{mol}^{-1}\right)$. Based on the experimental results together with theoretical calculations of the precursor formation energies, they proposed the following surface chemistry mechanism depicted in Fig. 5.

Similar studies were also carried out for other ruthenium substituted carbonyls complexes by Lai et al. ${ }^{111}$ They reported a new class of (amak)H ligands that is fluoro alcohol molecules with pendant amine functional group similar to the structure of $\beta$-diketonate ligand (hfac) $\mathrm{H}$ as depicted in Fig. 6.

Mostly, the (amak)H ligand having an amino group and an ionized alkoxy group, reacts with the cationic metal centre and forms stable five membered metallacycle arrangements. ${ }^{\mathbf{1 1 2}}$ The (amak)H ligands possess two electron-withdrawing $\mathrm{CF}_{3}$ groups and enhance the acidity $\left(\mathrm{p} K_{\mathrm{a}}=5.35-6.39\right),{ }^{113}$ reactivity and

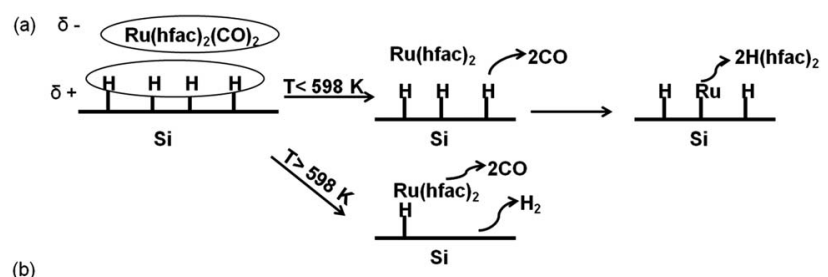

(b)

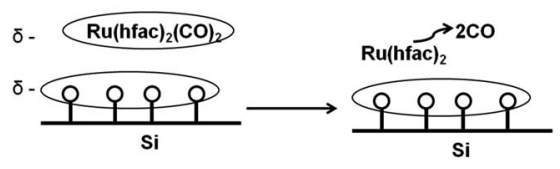

Fig. 5 Reaction mechanism proposed for $\left[\mathrm{Ru}(\text { hafc })_{2}(\mathrm{CO})_{2}\right]$ on both (a) $\mathrm{H}$-terminated and (b) $\mathrm{OH}$-terminated $\mathrm{Si}(100)$ surfaces. Adapted from ref. 109.

volatility in comparison to amino acids. So the (amak)H ligand is very suitable for the preparation of volatile metal chelate complexes for MOCVD applications. They (Lai et al.) ${ }^{\mathbf{1 0 8}}$ reported a series of ruthenium complexes $\left[\mathrm{Ru}(\mathrm{CO})_{2}(\text { amak })_{2}\right](\mathrm{R}=13: \mathrm{H}$, 14: $\mathrm{Me})$ and $\left[\mathrm{Ru}-(\mathrm{COD})(\mathrm{amak})_{2}\right]$ where $\mathrm{COD}=1,4$-cyclooctadiene and $\mathrm{R}=$ 15: $\mathrm{H}, 16$ : Et, 17: $\left.\left.\left(\mathrm{CH}_{2}\right)_{2} \mathrm{OMe}\right)\right)$ by the direct reaction of fluorinated amino alkoxide (amak)H with $\left[\mathrm{Ru}_{3}(\mathrm{CO})_{12}\right]$ and $\left[\mathrm{Ru}(\mathrm{COD}) \mathrm{Cl}_{2}\right]_{x}$ respectively as depicted in Scheme 2.

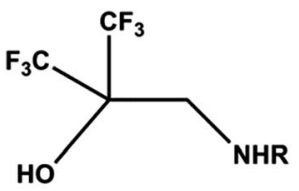

(amak)H $\mathrm{R}=\mathrm{H}, \mathrm{Me}, \mathrm{Et},\left(\mathrm{CH}_{2}\right)_{2} \mathrm{OMe}$

Fig. 6 Structure of (amak)H ligand similar to (hfac)H ligand adapted from ref. 109.

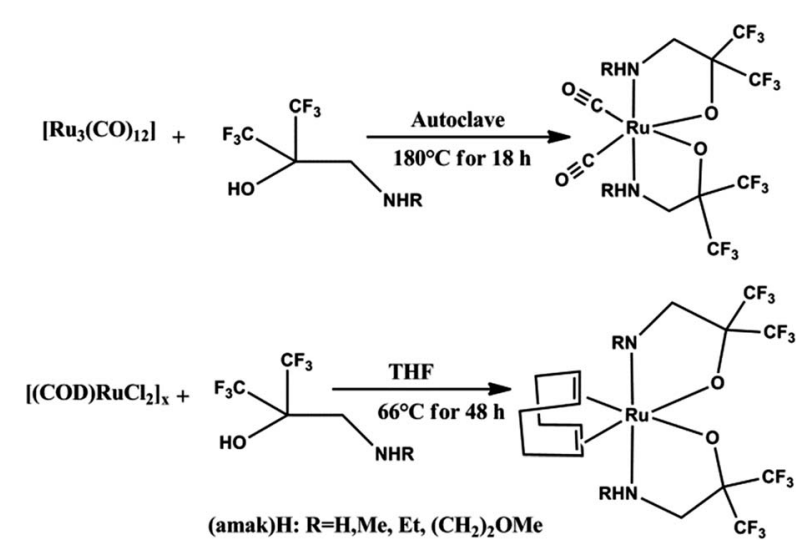

Scheme 2 Synthetic scheme for the preparation of $\left[\mathrm{Ru}(\mathrm{CO})_{2}(\mathrm{amak})_{2}\right]$ and $\left[\mathrm{Ru}-(\mathrm{COD})(\mathrm{amak})_{2}\right]$ complex. Adopted from ref. 112. 

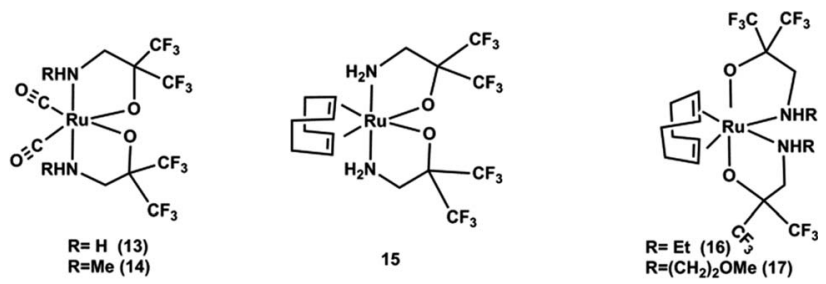

Fig. 7 Structure of $\left[\mathrm{Ru}(\mathrm{CO})_{2}(\mathrm{amak})_{2}\right]$ and $\left[\mathrm{Ru}-(\mathrm{COD})(\mathrm{amak})_{2}\right]$ complexes. Adapted from ref. 112.

A single crystal X-ray diffraction study ${ }^{112}$ showed that the carbonyl derivative of ruthenium complexes (such as 13, 14) exhibit only one type of structure with cis carbonyl ligands and with oxygen atoms of chelating amino alkoxides located trans to the carbonyl ligands. Whereas, the COD based ruthenium complexes show two distorted skeletal arrangements: one with cis amine functional groups (complex 15), while the second has trans amino groups and with alkoxide oxygen atoms located at cis to COD ligand (complex 16, 17), as shown in Fig. 7.

These complexes showed very good thermal stability and volatility. ${ }^{112}$ Only complexes $\mathbf{1 3}$ and $\mathbf{1 6}$ were selected for CVD studies because of their higher volatility and lower melting point. ${ }^{112}$ The deposition took place at temperatures of 325$425{ }^{\circ} \mathrm{C}$ in the presence of both $\mathrm{H}_{2}$ and a mixture of $2 \% \mathrm{O}_{2}$ in argon as carrier gas. Complex 13 deposited lustrous, silver-gray colored thin films which adhered very well to the substrate surface at $375{ }^{\circ} \mathrm{C}$ using $\mathrm{H}_{2}$ as carrier gas. Hexagonal $C$-axis oriented $\mathrm{Ru}$ thin films with (001) preferential orientation were deposited on glass substrates in a mixture of argon and ambient $\mathrm{O}_{2}$. By switching to the COD complex 16, Ru thin film with dense and smooth surface morphology can be obtained at a temperature as low as $325{ }^{\circ} \mathrm{C}$ under the mixed carrier gas.

\section{(b) Organometallic ruthenium derivatives}

Organometallic compounds of ruthenium with especially hydrocarbyl containing like alkyl, allyl, olefin or cyclopentadienyl groups were found to be suitable precursors in chemical vapor depoisition. ${ }^{114}$ The presence of hydrocarbyl precursors facilitate the thermal and/or photolytic decomposition to provide bare metal atoms condensing to form thin films of especially of nanoparticle size which are often also free from any contamination. ${ }^{115}$ In this process, the Ru-adsorbate bond plays an important role in thin film formation.

In this class of ruthenium compounds, several compounds based on cyclopentadienyl ligands have been prepared and studied as CVD precursor. ${ }^{116-127}$ The ligands attached to $\mathrm{Ru}(0)$ are shown in Fig. 8.

Ruthenocenes $\mathbf{1 7}$ are widely applied in the preparation of resistors; they are also used as additives to liquid crystals and for plating of multilayer electrodes with oxides and metals. The plasma induced vapor phase decomposition of ruthenocenes was used to produce metallic films at sufficiently high rate. ${ }^{116,117}$ Ruthenocene (rutheniumdicyclopentadienyl) was first synthesized in 1952 by Geoffrey Wilkinson, a Nobel laureate who assigned the structure of ferrocene only a year earlier.

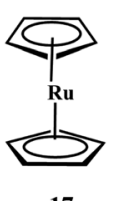

17

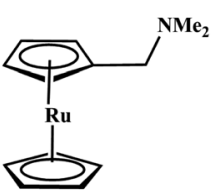

20

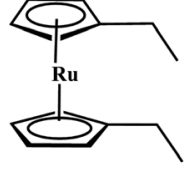

$17 \mathbf{a}$

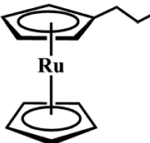

18

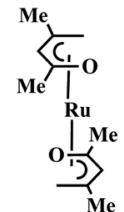

19

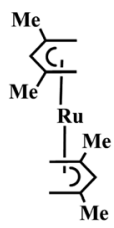

21

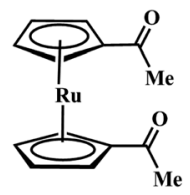

22
Fig. 8 The structure of some ruthenium cyclopentadienyl compounds.

Originally, ruthenocene was prepared by the reaction of ruthenium tris-acetonate with excess of cyclopentadienyl magnesium bromide. ${ }^{118-120}$ Ruthenocene may also be prepared by the reaction of the sodium salt of cyclopentadiene with ruthenium dichloride as depicted in following Scheme 3.

Aoyama et al. reported polycrystalline columnar ruthenium films deposited by liquid source chemical vapor deposition using ethylcyclopentadienyl)ruthenium $\left[\mathrm{Ru}\left(\mathrm{C}_{2} \mathrm{H}_{5} \mathrm{C}_{5} \mathrm{H}_{4}\right)_{2}\right]$ as precursor yielding films with low resistivity, small tensile stress, and excellent step coverage. ${ }^{121}$ The complex $\left[\mathrm{Ru}\left(\mathrm{C}_{2} \mathrm{H}_{5} \mathrm{C}_{5} \mathrm{H}_{4}\right)_{2}\right]$ allows a repeatable and reproducible delivery in vapor form into the CVD reactor and is found very useful in the production of capacitor electrodes [(ethylcyclopentadienyl)ruthenium(II)] $17 \mathrm{a}^{122,123}$ have been fairly explored as CVD precursors. Although this precursor can be used to produce pure films of low resistivity when reacted with oxygen however the growth rates are very low or not reported. ${ }^{116}$ Therefore, another group of scientists including Nabatame $e t$ al. explored liquid source chemical vapor deposition from bis-(ethylcyclopentadienyl)ruthenium dissolved in THF and obtained pure ruthenium thin films deposited on $\mathrm{SiO}_{2} / \mathrm{Si}$ substrates. ${ }^{124}$ Later on, Kim et al. ${ }^{125}$ also reported $\left[\mathrm{Ru}(\mathrm{EtCp})_{2}\right] \mathbf{1 7 a}$ as precursor for $\mathrm{Ru}$ and $\mathrm{RuO}_{2}$ composite films grown on TiN/Ti/Si substrate by MOCVD. They investigated iodine sources $\left(\mathrm{CH}_{3} \mathrm{I}, \mathrm{C}_{2} \mathrm{H}_{5} \mathrm{I}\right)$ for improving the smoothness of the film surface at $300{ }^{\circ} \mathrm{C}$ for its application as a bottom electrode of a high density DRAM capacitor and reduce the leakage characteristics of Ru electrodes. As iodine containing sources were introduced during the deposition, a

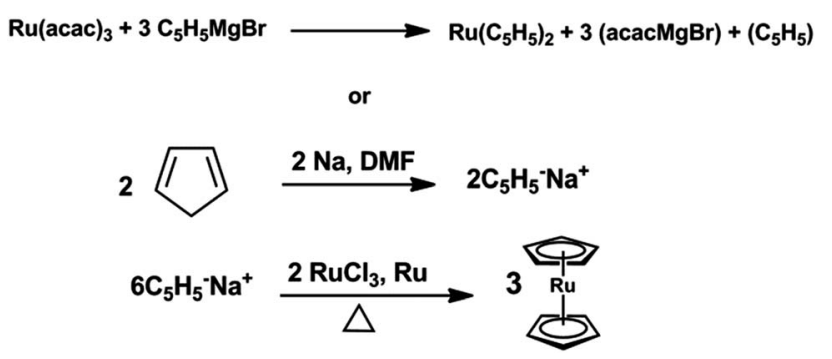

Scheme 3 Preparation methods of ruthenocene. 
dramatically enhanced nucleation of thin film was observed at the initial deposition stage and the surface roughness of the films was reduced considerably without affecting crystallinity or the deposition rate of the composite films.

Further in 2006, Hur'yeva et al. explored pure ruthenium thin films by liquid-delivery metal-organic (MO)CVD in toluene in the temperature range of $330-460{ }^{\circ} \mathrm{C}$ via an oxygen-assisted pyrolysis. ${ }^{44}$ The deposition of ruthenium thin films was controlled by surface reaction kinetics as the rate-limiting step (with an activation energy of $1.4 \mathrm{eV}$ that is $135.1 \mathrm{~kJ} \mathrm{~mol}^{-1}$ ) below $400{ }^{\circ} \mathrm{C}$.

$\mathrm{Ru}$ thin films grown by $\left[\mathrm{Ru}(\mathrm{EtCp})_{2}\right]$ showed good properties such as low electrical resistivity, high deposition rates, and low impurity concentrations; however, $\left[\mathrm{Ru}(\mathrm{EtCp})_{2}\right]$ is very expensive and thus not suited for CVD in a mass production stage. Therefore, there is still a need of new precursors that can have a comparable performance as required. One high-growth rate precursor developed, is cyclopentadienyl-propylcyclopentadien ruthenium(II) [RuCp(i-PrCp)] 18. ${ }^{126}$ A [RuCp(i-PrCp)] complex leads to single phase metallic ruthenium films under all deposition conditions with growth rates of $7.5 \mathrm{~nm} \mathrm{~min}^{-1}$ to $20 \mathrm{~nm}$ $\min ^{-1}$ also with a low resistivity $(12 \mu \Omega \mathrm{cm})$ at the $\mathrm{Ru} / \mathrm{TiN}$ interface. The interface between $\mathrm{Ru}$ and TiN was not changed even after annealing at $600{ }^{\circ} \mathrm{C}$ under a $\mathrm{N}_{2}$ atmosphere because of negligible amount of residual oxygen content. However, films showed a poor nucleation behaviour both on $\mathrm{SiO}_{2}$ surfaces as well as on $\mathrm{Ta}_{2} \mathrm{O}_{5}$ surfaces owing to the non wetting behaviour of $\mathrm{Ru}$ on $\mathrm{SiO}_{2}$ resulting in a rough surface morphology or very small film thicknesses respectively. The decrease in film growth rate indicated an increased stress which also affected the nucleation behaviour through intrinsic stress generation by zipping of the nuclei. This phenomenon was explained by a diffusive stress relaxation mechanism. ${ }^{127}$

Complex 17 was used in preparation of complex 26-28 in 7, 14,23 and $73 \%$ yield respectively as shown in Scheme 4 . On prima facie, one can understand that complexes 23 and 24 lead to self assembled structure (bimolecular or more), because they
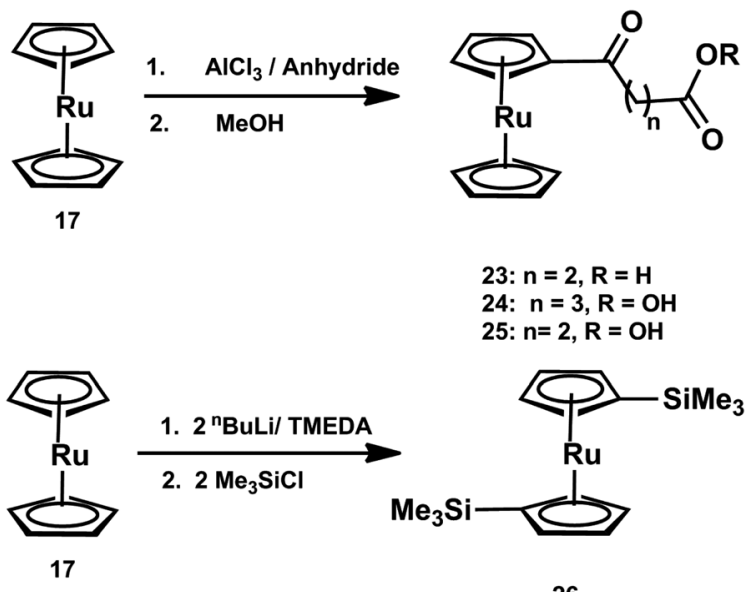

26

Scheme 4 Synthetic strategy followed for the preparation of complexes 23-26. Adapted from ref. 128. contain carboxyl groups. However, to understand the quantitative differences in the reactivity of such ruthenocenes at least a theoretical investigation is required by optimizing the structures and calculating the electron density on each molecule. The physical properties of such molecules reported by Siddiqi et $a{ }^{128}$ could be taken into consideration to correlate their physical properties with the localization of electron density on ruthenium atom or on the molecular skeleton as a whole. It is concluded that 17-26 are most thermally stable molecule good volatility for CVD application.

It is well known that introduction of trimethylsilyl groups in ruthenocenes resulted in both high vapor pressures and low melting points. ${ }^{\mathbf{1 2 9}}$ Recently, Tuchscherer et al. ${ }^{\mathbf{1 3 0}}$ reported synthesis, characterization and application of a series of trimethylsilyl, l-tert-butyl-substituted and half open ruthenocenes as CVD precursors for ruthenium thin film deposition. The complexes were characterized by single crystal X-ray diffraction and their synthetic route is depicted in Scheme 5 and 6. All these ruthenocenes evaporate without decomposition at atmospheric pressure. The highest volatility among all ruthenocenes was found for $\mathbf{3 1}$ and $\mathbf{3 2}$. It was also observed that the deposition temperature increases with the number of $\mathrm{SiMe}_{3}$ groups. All complexes are found to be good precursors for MOCVD. The ruthenium film depositions on $\mathrm{Si} / \mathrm{SiO}_{2}$ targets were carried out

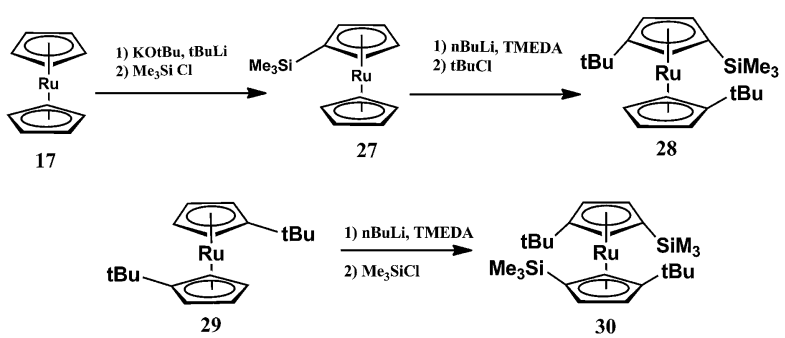

Scheme 5 Synthesis protocol for the preparation of ruthenocenes 28 and 30 . Adapted from ref. 130.
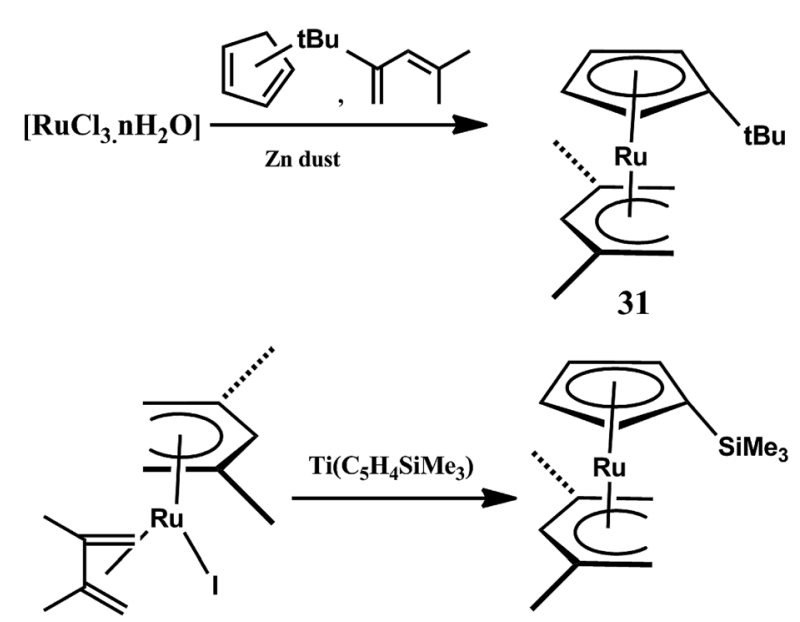

32

Scheme 6 Synthesis protocol for the preparation of half open ruthenocenes 31 and 32. Adapted from ref. 130. 


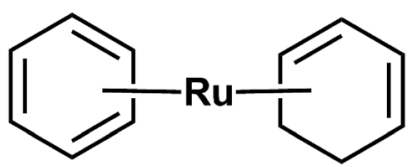

33

Fig. 9 Structure of ( $\eta^{6}$-benzene) $\left(\eta^{4}-1,3\right.$ cyclohexadiene) ruthenium, $\mathrm{Ru}\left(\mathrm{C}_{6} \mathrm{H}_{6}\right)\left(\mathrm{C}_{6} \mathrm{H}_{8}\right)$.

in the temperature range of $633-688 \mathrm{~K}$ with a flow rate of $50 \mathrm{~mL}$ $\min ^{-1}$ using nitrogen as the carrier gas. Pure ruthenium thin films were formed from $t \mathrm{Bu}$-functionalized ruthenocenes 29 and 31, while mixed ruthenium $/ \mathrm{SiO}_{2}$ layers were obtained from 27, 28, 29 and 32. The appropriate layers possess thicknesses between 75-135 $\mathrm{nm}$ and are conformal and dense as proven by SEM, EDX spectroscopy, and XPS studies.

Another family of ruthenium CVD precursors includes ruthenium arene-diene compounds of the type $\left[\mathrm{Ru}\left(\eta^{6}\right.\right.$ $\left.\mathrm{C}_{6} \mathrm{H}_{5} \mathrm{R}\right)\left(\eta^{4}\right.$-diene $\left.)\right](\mathrm{R}=\mathrm{H}, \mathrm{Et}$, etc.; diene = 1,3-butadiene, 1,3hexadiene, 1,5-cyclooctadiene, etc.) allowing pure Ru deposition at relatively low temperatures. Ruthenium films obtained from $\left(\eta^{6}\right.$-benzene $)\left(\eta^{4}-1,3\right.$-cyclohexadiene $)$ ruthenium precursor complex (see Fig. 9) were deposited on a p-type(100)silicon substrate by MOCVD without any reaction gas. ${ }^{\mathbf{1 3 1}}$ The composition of the film was established using the elastic recoil detection time of flight (ERD-TOF) technique ${ }^{\mathbf{1 3 2}}$ using both, the flight time and the energy of the recoiled elements.

Further, Schneider et al. ${ }^{6}$ had also exploited [(benzene)(1,3cyclohexadiene) $\mathrm{Ru}(0)] \quad 33$ as a MOCVD precursor for the formation of ruthenium thin films. They investigated mainly the process parameters which promote the purity of the deposited ruthenium films without the help of a reactive gas. The experiments were performed with Si wafers as substrates at a total pressure of $50 \mathrm{mbar}$, substrate temperature range of 200$450{ }^{\circ} \mathrm{C}$, and helium carrier gas velocity of 1.5 to $16.5 \mathrm{~cm} \mathrm{~s}^{-1}$. The synthetic strategy for the preparation of [(benzene)(1,3-

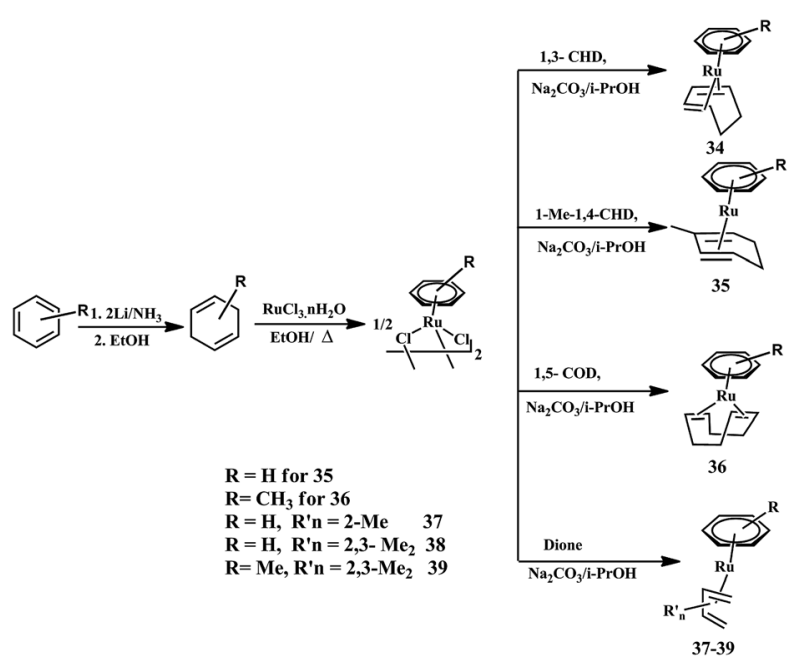

Scheme 7 Preparation method some closed and open ruthenocene. cyclohexadiene) $\mathrm{Ru}(0)$ ] is depicted in Scheme 7. Pure ruthenium films (with only $3 \mathrm{~mol} \%$ carbon impurity) were deposited at a substrate temperature of $300{ }^{\circ} \mathrm{C}$ and a carrier gas velocity of $12.8 \mathrm{~cm} \mathrm{~s}^{-1}$.

From Fig. 10, it is clearly observed that the formation of benzene by dehydrogenation of 1,3-cyclohexadiene takes place effectively in the surface reaction. ${ }^{6}$ The hydrogen obtained from the dehydrogenation could be trapped in the ruthenium film and is not removed by the carrier gas even at high flow velocities or high substrate temperatures. However, both ligands are directly connected by hydrogen transfer.

The formation of benzene from 1,3-cyclohexadiene is thermodynamically strongly favoured due to its low Gibbs energy of formation. From the experimental findings (GC), the reaction mechanism for the formation of ruthenium thin film from [(benzene)(benzene)(1,3-cyclohexadiene)Ru] was proposed ${ }^{6}$ and summarized in Scheme 8. The authors also established the

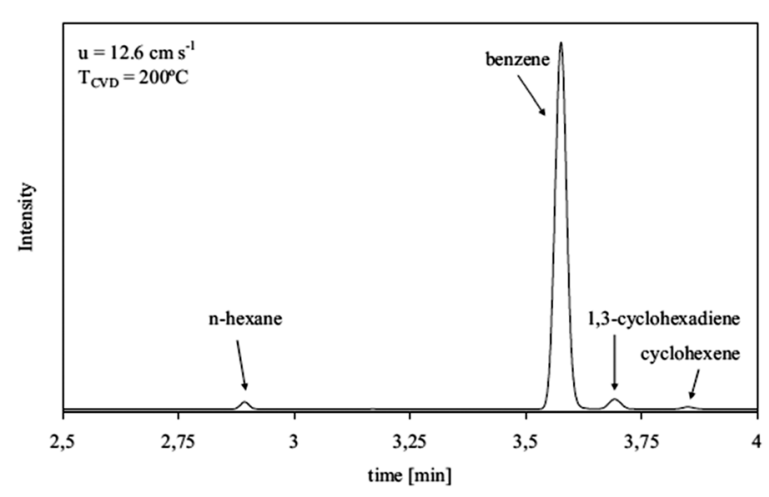

Fig. 10 Gas chromatogram of condensable organic by-products of the MOCVD formation of a thin ruthenium film with [(benzene)(benzene)(1,3-cyclohexadiene)Ru] as the precursor. Source ref. 6 .

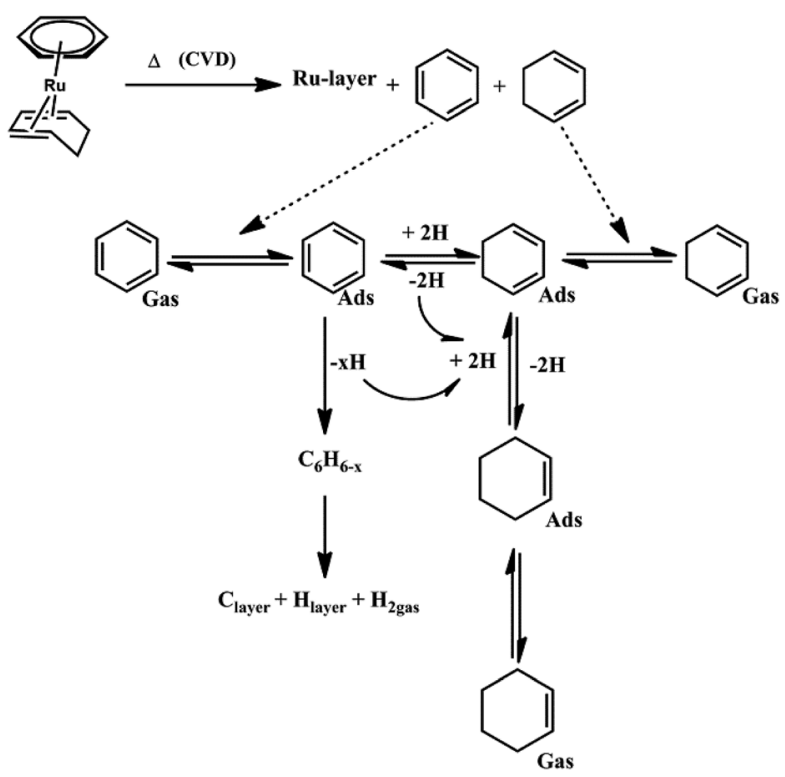

Scheme 8 Decomposition of [(benzene)(1,3-cyclohexadiene)Ru(0)] and ruthenium surface chemistry of its ligands. Adapted from ref. 6 . 
thermodynamic aspect of the adsorption/desorption equilibrium and calculated the gas phase equilibrium constant, $K$ as given in Table 3 for a total pressure of 50 mbar and at various temperatures.

Recently, Jipa et al. synthesized and characterized some methylated [(arene)(1,3-cyclohexadiene) $\mathrm{Ru}(0)]$ complexes such as [(benzene)(2-methyl-1,3-cyclohexadiene) $\mathrm{Ru}(0)] \quad \mathbf{3 5}^{\mathbf{1 3 3}}$ as shown in Scheme 7. Scheme 9 shows a possible reaction mechanism which follows the conversion of the 2-Me-1,3-CHD ligand of 35 into toluene without isomerization and reduction by a $\mathrm{C}-\mathrm{H}$ bond activation of adsorbed Me-CHD. ${ }^{133}$ The intermolecular hydrogen transfer processes, and the isomerisation of 2-Me-1,3-CHD also takes place, which lead to further MeCHD isomers without affecting the benzene ligand owing to its high stability.

Schneider et al. synthesized a half open ruthenium complex such as [(toluene)(1,5-cyclooctadiene)Ru(0)] 36 and deposited films on copper and silicon substrates in a vertical cold wall reactor. It led to the formation of thin metallic ruthenium films with low carbon content at $150-450{ }^{\circ} \mathrm{C} .{ }^{\mathbf{1 3 4}}$ Smooth homogeneous ruthenium thin films were obtained using He carrier gas at a pressure of $100 \mathrm{mbar}$ in the temperature range of 160$250{ }^{\circ} \mathrm{C}$. The synthetic path is shown in Scheme 7 .

The MOCVD process starting with precursor 36 showed that the decomposition of ligands into toluene and 1,5-COD with traces of the solvent $n$-hexane were found on the surface. ${ }^{135} n$ Hexane was used throughout the synthesis of $\mathbf{3 6}$ and assumed that it is not a decomposition product of the ligands. The reaction pathways are depicted in Scheme 10.

Jipa et al. also synthesized some methylated [(benzene)(1,3butadiene) $\mathrm{Ru}(0)]$ derivatives such as [(benzene)(2-methyl-1,3butadiene) $\mathrm{Ru}(0)]$ 37, [(benzene)(2,3-dimethyl-1,3-butadiene)

Table 3 Calculated temperature dependent gas phase, equilibrium constant. Source ref. 6

\begin{tabular}{llll}
\hline Reaction & \multicolumn{3}{l}{ Gas Phase equilibrium constant, $K(-)$} \\
\hline $\mathrm{C}_{6} \mathrm{H}_{8} \leftrightarrow \mathrm{C}_{6} \mathrm{H}_{6}+\mathrm{H}_{2}$ & $1.19 \times 10^{9}$ & $5.20 \times 10^{8}$ & $2.41 \times 10^{8}$ \\
$\mathrm{C}_{6} \mathrm{H}_{8}+\mathrm{H}_{2} \leftrightarrow \mathrm{C}_{6} \mathrm{H}_{10}$ & 6260 & 42.7 & 0.30 \\
Temperature, $T\left({ }^{\circ} \mathrm{C}\right)$ & 200 & 300 & 450
\end{tabular}

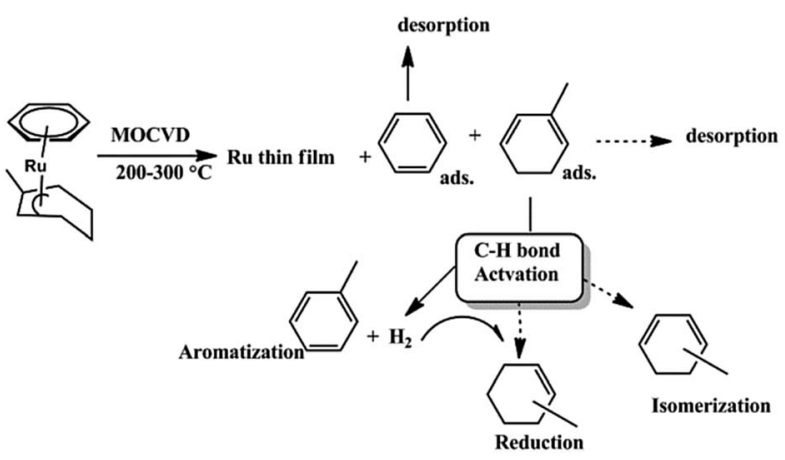

Scheme 9 MOCVD and follow-up chemistry of the ligands of complex 35 at $200-300{ }^{\circ} \mathrm{C}$ substrate temperature. Adapted from ref. 133.

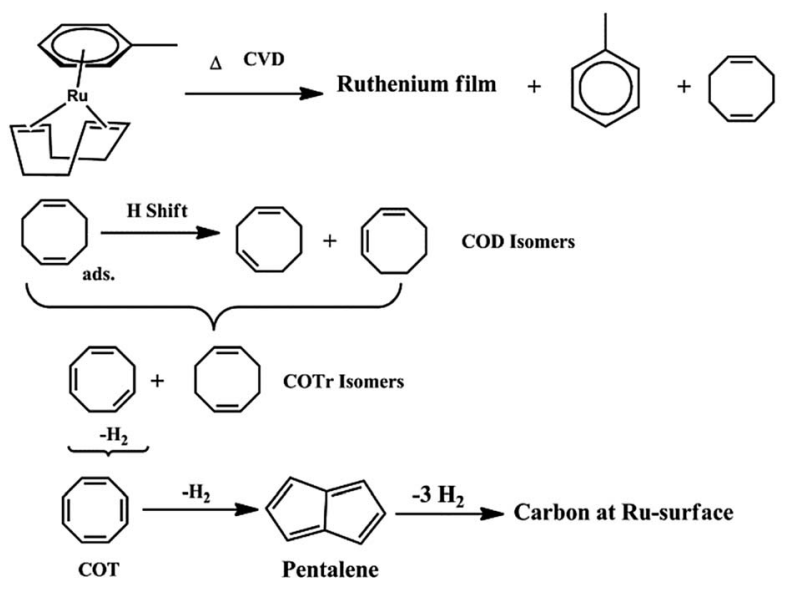

Scheme 10 Basic CVD Process of 36 and isomerization and dehydrogenation of the dissociated ligands 1,5-COD at the ruthenium surface. Adapted from ref. 135.

$\mathrm{Ru}(0)] 39$ and [(2,3-dimethyl-1,3-butadiene)(toluene) $\mathrm{Ru}(0)] 38$ as novel MOCVD precursors with favorable deposition properties for thin polycrystalline ruthenium films with a low surface roughness as shown in scheme $7 .{ }^{\mathbf{1 3 5}}$ Polycrystalline thin ruthenium films with rough surface were deposited on silicon wafers at 200 and $400{ }^{\circ} \mathrm{C}$ substrate temperatures in a nitrogen gas atmosphere. The reaction kinetics starts with the activation of $\mathrm{C}-\mathrm{H}$ and $\mathrm{C}-\mathrm{C}$ bonds of hydrocarbons with the complex as a highly active Fischer-Tropsch catalyst and forms thin ruthenium films on the surface as depicted in Scheme 11.

Among the different sources of ruthenium mentioned above, [Ru(DMPD)(EtCp)], (DMPD = 2,4-dimethylpentadienyl, EtCp = ethylcyclopentadienyl) showed the best physical properties which makes it a promising precursor of MOCVD as depicted in Fig. 11. It showed sufficient stability, fine volatility, and low viscosity. It has a lower deposition temperature $\left(60^{\circ} \mathrm{C}\right)$, a short incubation time, a smoother surface and higher nucleation density at the initial stage of deposition. The most advantageous characteristic of this compound is that it can be used to deposit a stable conformal Ru film on 3D structured substrates without a $\mathrm{Ru}$ seed layer as it has a linear-dienyl ligand, 2,4pentadienyl(DMPD) $\mathbf{4 0}$ instead of an allyl-substituted cyclopentadienyl ligand $\mathbf{4 3}$ in its precursor.

In this context, Kawano et al. ${ }^{\mathbf{1 3 6}}$ had reported that decomposition temperature of $[\mathrm{Ru}(\mathrm{DMPD})(\mathrm{EtCp})] \mathbf{4 0}$ was $270{ }^{\circ} \mathrm{C}$, which was $80{ }^{\circ} \mathrm{C}$ lower than that of $\left[\mathrm{Ru}(\mathrm{EtCp})_{2}\right]$. It owes to

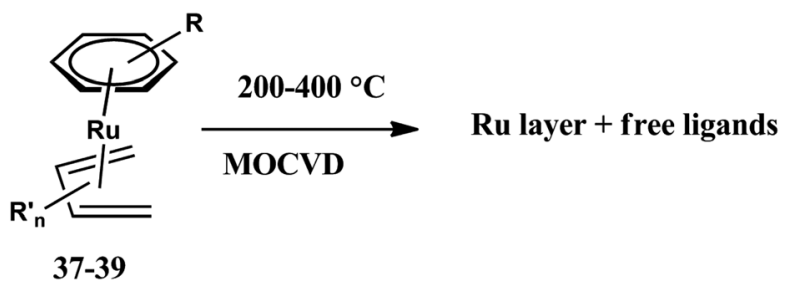

Scheme 11 Ru layer formation from complexes 37-39. Adapted from ref. 127. 


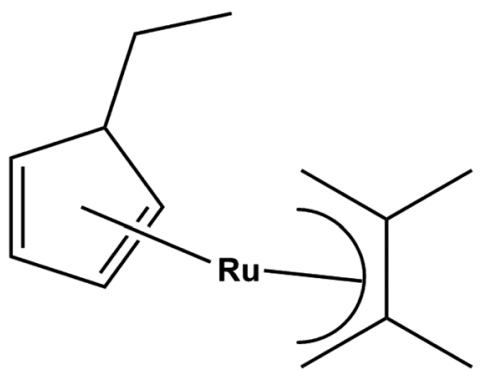

40

Fig. 11 Molecular structure of [Ru(DMPD)(EtCp)] 40

change of one ligand from alkyl-substituted cyclopentadienyl group to an alkyl-substituted linear pentadienyl group. The $\left[\mathrm{Ru}(\mathrm{DMPD})_{2}\right]$ with two alkyl-substituted linear pentadienyl ligand decomposed at $210{ }^{\circ} \mathrm{C}$ which is $60{ }^{\circ} \mathrm{C}$ lower than $[\mathrm{Ru}(\mathrm{DMPD})(\mathrm{EtCp})]$. Thus, it showed that $\left[\mathrm{Ru}(\mathrm{DMPD})_{2}\right.$ may be a useful MOCVD precursor.

The study ${ }^{136}$ showed that $\left[\mathrm{Ru}(\mathrm{DMPD})_{2}\right]$ can be used in a wider range of deposition temperature in the transported limited temperature regime as compare to [Ru(DMPD)(EtCp)]. The thin films of $\left[\mathrm{Ru}(\mathrm{DMPD})_{2}\right]$ can be deposited below $200{ }^{\circ} \mathrm{C}$ whereas film deposition for [Ru(DMPD)(EtCp)] was found only above $250{ }^{\circ} \mathrm{C}$.

One interesting dinuclear complex of cyclopentadiene $\left[\mathrm{Ru}\left(\mathrm{C}_{5} \mathrm{H}_{5}(\mathrm{CO})_{2}\right)_{2}\right] \mathbf{4 1}$ as shown in Fig. 12, formed pure, conductive, conformal ruthenium films on patterned $\mathrm{Si}_{3} \mathrm{~N}_{4}$ and on flat barium strontium titanate BST in the presence of oxygen carrier gas. ${ }^{137}\left[\mathrm{Ru}\left(\mathrm{C}_{5} \mathrm{H}_{5}(\mathrm{CO})_{2}\right)_{2}\right] \mathbf{4 1}$ has labile $\mathrm{CO}$ ligands as leaving groups decrease the decomposition temperature (Fig. 12).

Pure $\mathrm{Ru}$ thin films were deposited on $\mathrm{Si}$ substrate using $\left[\mathrm{Ru}(\mathrm{OD})_{3}\right] \mathbf{4 2}(\mathrm{OD}=$ octanedionate $)$ by metalorganic chemical vapor deposition (MOCVD). The study showed that deposition of thin film depend on MOCVD process parameters such as deposition temperature, $\mathrm{O}_{2} /\left(\mathrm{O}_{2}+\mathrm{Ar}\right)$ ratio, and reactor pressure..$^{138,139}$

Cyclopentadienyl complexes of previously synthesized ruthenium allylic derivative such as $\left[\mathrm{Ru}\left(\eta^{3}-\mathrm{C}_{3} \mathrm{H}_{5}\right)_{2}(\mathrm{COD})\right] \mathbf{4 3}$ (Fig. 13), $\mathrm{COD}=1,4$-cyclooctadiene, ${ }^{140}$ had been extensively studied as CVD precursor at low temperatures on $\alpha-\mathrm{Al}_{2} \mathrm{O}_{3}$ and surface oxidized $\mathrm{Si}(100)$ in $\mathrm{N}_{2}, \mathrm{~N}_{2}+\mathrm{H}_{2}, \mathrm{~N}_{2}+\mathrm{O}_{2}$, or $\mathrm{O}_{2}$ flow. ${ }^{141}$ It was observed that $\mathrm{H}_{2}$ addition increased the metal purity and decreased the grain sizes.

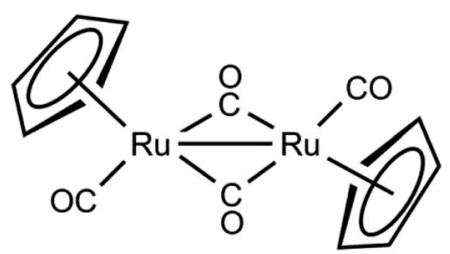

Fig. 12 Molecular structure of $\left[\mathrm{Ru}\left(\mathrm{C}_{5} \mathrm{H}_{5}(\mathrm{CO})_{2}\right)_{2}\right] 41$.

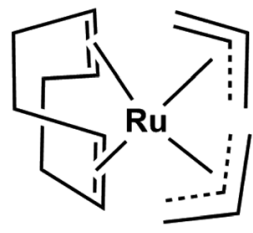

43

Fig. 13 Molecular structure of $\left[\mathrm{Ru}\left(\eta^{3}-\mathrm{C}_{3} \mathrm{H}_{5}\right)_{2}(\mathrm{COD})\right] 43$.

Barison et al. also studied nanocrystalline $\mathrm{RuO}_{2}$ and $\mathrm{Ru}$ films obtained from $\operatorname{Ru}(\mathrm{COD})\left(\eta^{3} \text {-allyl }\right)_{2}(\mathrm{COD}=$ cycloocta-1,5-diene $)$ on metallic titanium discs at a temperature of $300{ }^{\circ} \mathrm{C}$ by the electrocatalytic $\mathrm{O}_{2}$ evolution. ${ }^{142,143}$

Recently, Ando et al. ${ }^{144}$ reported the synthesis of a series of $\mathrm{Ru}(0)$ cyclooctatetraene complexes for MOCVD (metal organic chemical vapor deposition) applications. A melting point relation of the CVD precursors is reported and shown in Fig. 14. The melting point increases with the decrease in alkyl substituent at cyclooctatetraene ring.

The synthetic strategy of $\mathrm{Ru}(0)$ COT complexes, [ $\left(\eta^{4}\right.$-COT$\left.\mathrm{R})(\mathrm{CO})_{3} \mathrm{Ru}(0)\right](\mathrm{R}=\mathrm{H}: \mathbf{4 4}$, Me: 45, Et: 46), COTR = R-cycloocta1,3,5,7-tetraene for MOCVD is depicted in scheme 12. Conformal ruthenium films were deposited on $\mathrm{SiO}_{2}$ substrates even within holes with aspect ratios of $40: 1$. The ruthenium film formation improves by the introduction of methyl and ethyl group into the COT ligand.

\section{(c) Ruthenium derivatives containing $\mathrm{N}$-donor ligands}

$\mathrm{N}$-donor ligands may be an interesting alternative to the precursors discussed so far. Since CVD precursors are mostly governed by the ligand frameworks, it may be helpful to enlist some selected nitrogen donors in Fig. 15. These nitrogen donors were used as ligands in transition metal complexes. ${ }^{145}$
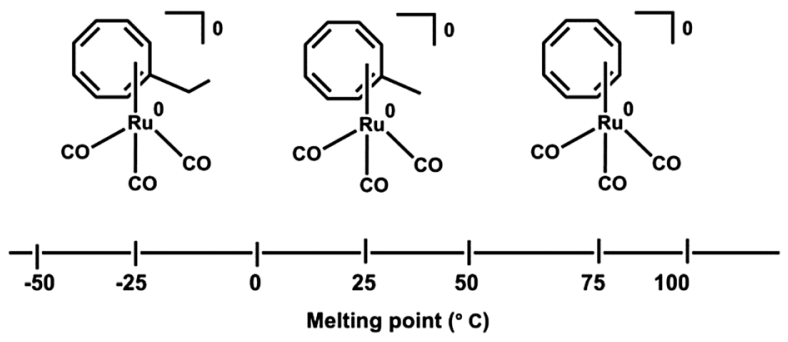

Fig. 14 Structure and Melting points CVD precursor 44-46. Adapted from ref. 144.

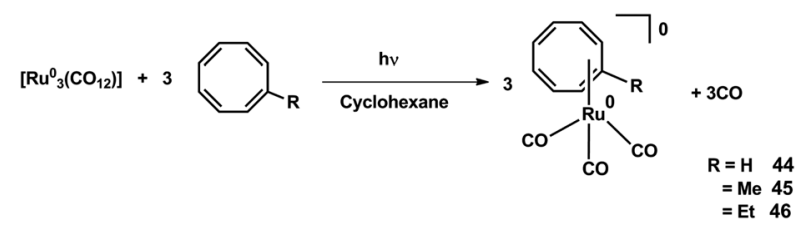

Scheme 12 Synthesis of CVD precursor 44-46. Adapted from ref. 144. 


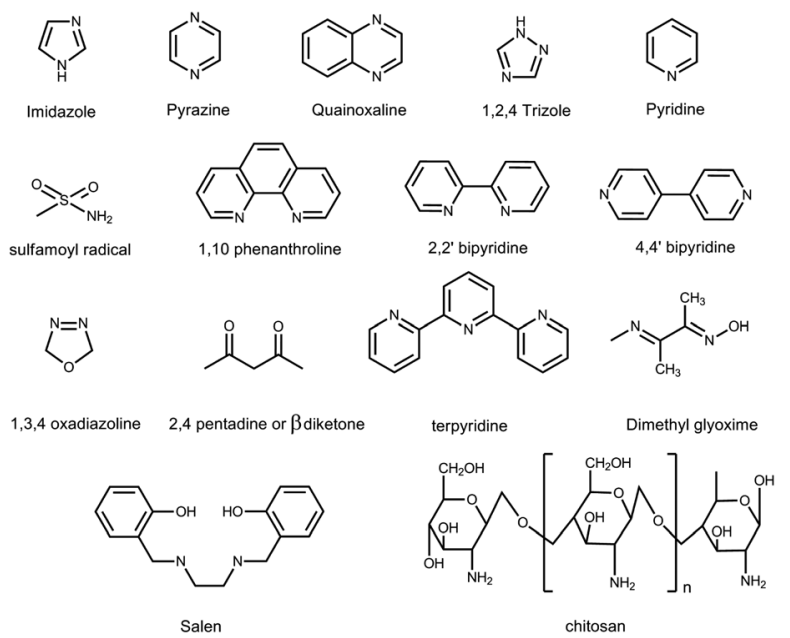

Fig. 15 Some nitrogen donor ligands.

In 2003, Carty and co-workers reported the synthesis and structure of double pyrazolate bridged ruthenium complexes $\left[(\mathrm{CO})_{3} \mathrm{Ru}\left(3,5-\left(\mathrm{CF}_{3}\right)_{2} \mathrm{Pz}\right)\right]_{2} 47$ and $48\left\{3,5-\left(\mathrm{CF}_{3}\right)_{2} \mathrm{Pz}=3,5\right.$-bis(trifluoromethyl)pyrazole $\}$ at low temperature $180{ }^{\circ} \mathrm{C}$ which exhibited superior volatility as compared to its parent compound $\mathrm{Ru}_{3}(\mathrm{CO})_{12}$ and closely related 3,5,di-tert-butyl pyrazole complex $\left[\mathrm{Ru}_{2}(\mathrm{CO})_{5}\left(3,5-t-\mathrm{Bu}_{2}-\mathrm{pz}\right)_{2}\right]$ for its practical use in CVD. ${ }^{146,147}$ The introduction of $\mathrm{CF}_{3}$ groups in pyrazole moiety increases the volatility of the bridged ruthenium complex 47 as compared to complex 48 . The synthetic route for the preparation is shown in Scheme 13 and the structure of the complex as derived from X-ray diffraction is depicted in Fig. 16.

Chou et al. ${ }^{78}$ synthesized two octahedral Ru(III) complexes such as $\left[\mathrm{Ru}(\operatorname{keim} 1)_{3}\right] \mathbf{4 9}$ and $\left[\mathrm{Ru}(\operatorname{keim} 2)_{3}\right]$ 50, $(\operatorname{keim} 1=$ $-\mathrm{OC}\left(\mathrm{CF}_{3}\right)=\mathrm{CHC}-\mathrm{CH}_{3}=\mathrm{NMe}$, keim $2=-\mathrm{OC}\left(\mathrm{CF}_{3}\right)=\mathrm{CHC}-\mathrm{CF}_{3}=$ $\mathrm{NMe}$ ) with good volatility and thermal stability. The CVD study showed that the film structures varied according to the nature of source reagent and carrier gas. $\left[\mathrm{Ru}(\mathrm{keim} 1)_{3}\right]$ lead to the formation of a (002) preferred orientation using a mixture of $2 \%$ $\mathrm{O}_{2}$ in argon or pure $\mathrm{O}_{2}$ as carrier gas, while $\left[\mathrm{Ru}(\mathrm{keim} 2)_{3}\right]$ yielded a randomly oriented $\mathrm{Ru}$ thin film. The physical properties such as temperature, of the complexes can seriously affect the kinetics and mechanism of $\mathrm{RuO}_{2}$ growth behaviour. The formation of (200) growth of $\mathrm{RuO}_{2}$ columnar thin films is

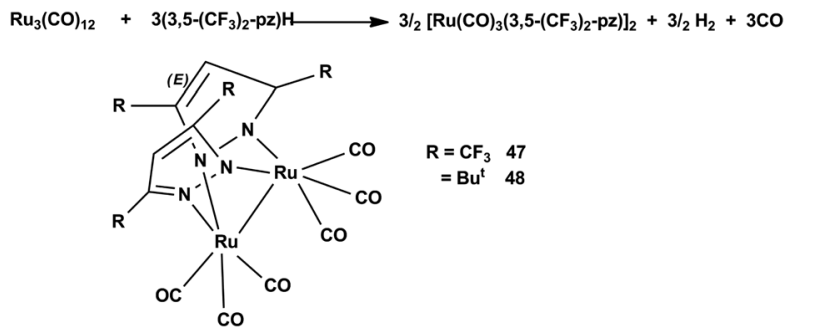

Scheme 13 Synthesis and molecular structure of pyrazolate bridged ruthenium complexes. Adapted from ref. 147.

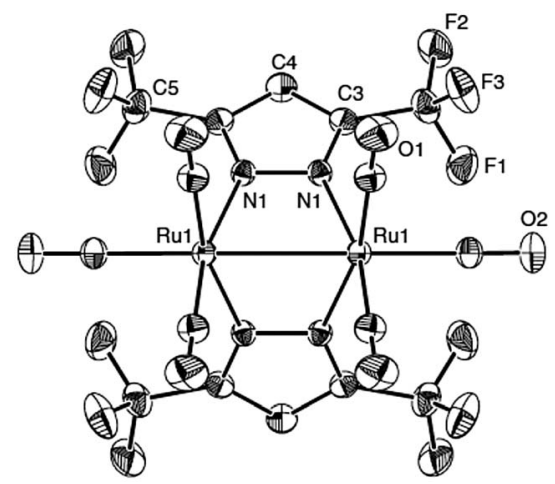

Fig. 16 The structure of pyrazolate bridged ruthenium complex. Source ref. 147.

observed when $\left[\mathrm{Ru}(\mathrm{keim} 1)_{3}\right]$ is used in pure $\mathrm{O}_{2}$ carrier gas at 1 atm below $270{ }^{\circ} \mathrm{C}$ (Fig. 17).

Li et al. reported high purity ( $0.2 \%$ impurities) fine-grained polycrystalline ruthenium thin film deposition obtained from a volatile ruthenium amidinate precursor $\left[\mathrm{Ru}(\mathrm{Bu}-\mathrm{Me}-\mathrm{amd})_{2}(\mathrm{CO})_{2}\right]$ 51, bis( $N, N$-di-tert-butylacetamidinato) ruthenium(II)dicarbonyl without any coreactant via pulsed CVD at above $300{ }^{\circ} \mathrm{C} .{ }^{\mathbf{1 4 8}}$ The molecular structure and crystal structure of $\mathrm{Ru}$ amidinate precursor as shown in Fig. 18 and 19.

For thin film formation, they proposed a thermal decomposition mechanism as shown in Scheme 14. It shows that $\left[\mathrm{Ru}(\mathrm{Bu}-\mathrm{Me}-\mathrm{amd})_{2}(\mathrm{CO})_{2}\right] \mathbf{5 1}$ decomposes by releasing carbon monoxide and the ligand dimer.
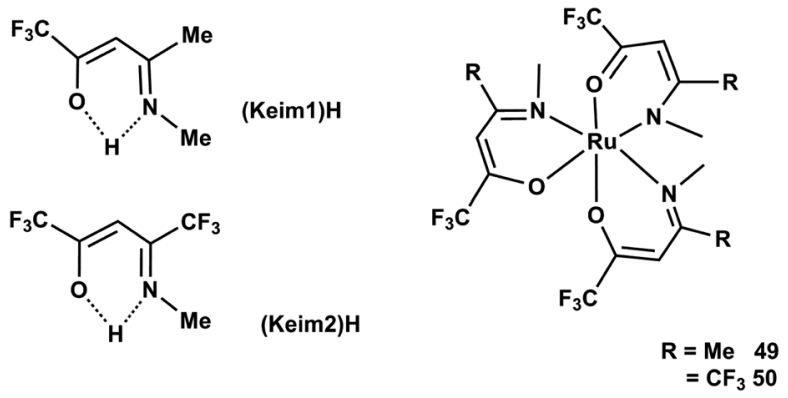

Fig. 17 Structure of $\mathrm{CF}_{3}$ substituted ketoimine ligands.

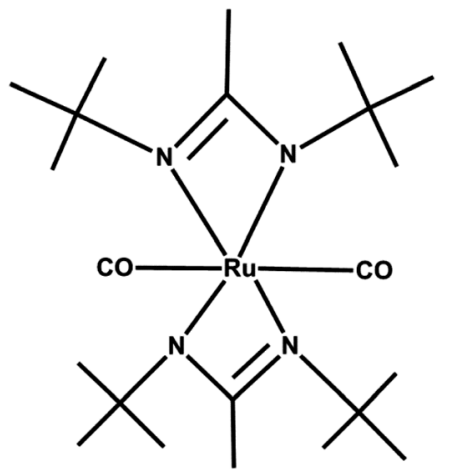

Fig. 18 Molecular structure of $\left[\mathrm{Ru}(\mathrm{Bu}-\mathrm{Me}-\mathrm{amd})_{2}(\mathrm{CO})_{2}\right] 51$. 


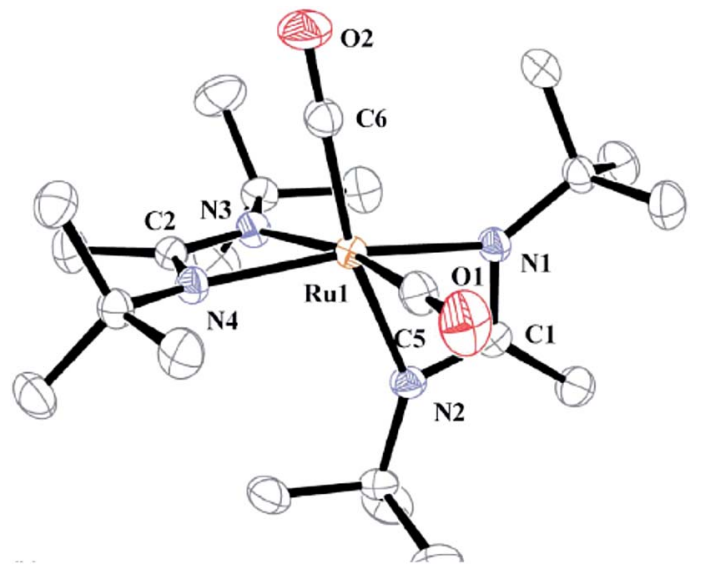

Fig. 19 Crystal structure of $\left[\mathrm{Ru}(\mathrm{Bu}-\mathrm{Me}-\mathrm{amd})_{2}(\mathrm{CO})_{2}\right]$.

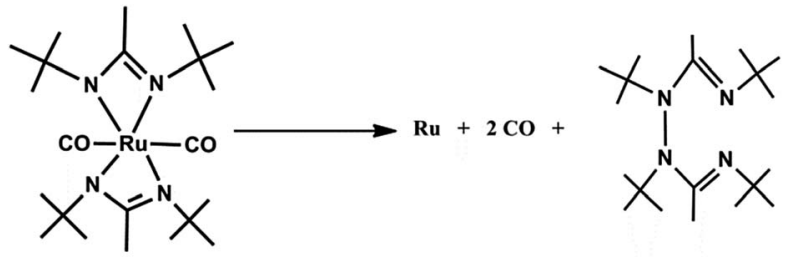

Scheme 14 Mechanism of ruthenium thin deposition from [Ru(Bu$\mathrm{Me}-\mathrm{amd})_{2}(\mathrm{CO})_{2}$. Adapted from ref. 136.

In this class of ruthenium complexes, three new amidinate complexes of types tris(diisopropylacetamidinato)-ruthenium(III) $\quad\left[\mathrm{Ru}(\mathrm{iPrNC}(\mathrm{Me}) \mathrm{NiPr})_{3}\right] \quad \mathbf{5 2}, \quad$ bis(diisopropyl-acetamidinato)ruthenium(II) dicarbonyl $\left[\mathrm{Ru}(\mathrm{iPrNC}(\mathrm{Me}) \mathrm{NiPr})_{2}\right.$ $\left.(\mathrm{CO})_{2}\right] \quad 53$ and bis(di-tert-butylacetamidinato)ruthenium(II) dicarbonyl $\left[\mathrm{Ru}(t \mathrm{BuNC}(\mathrm{Me}) \mathrm{NtBu})_{2}(\mathrm{CO})_{2}\right], \mathbf{5 4}$ were found to be sufficiently volatile and thermally stable and thus suitable for chemical vapor deposition. ${ }^{149}$ A schematic view of their synthesis is shown in Scheme 15. Starting materials mer$\mathrm{RuCl}_{3}(\mathrm{MeS})_{3}, \quad\left[\mathrm{RuCl}_{2}(\mathrm{CO})_{3}\right]_{2}$, and $\operatorname{RuCl}_{2}(\mathrm{CO})_{3}\left(\mathrm{C}_{4} \mathrm{H}_{8} \mathrm{O}\right)$ which have relatively high solubility in ether or THF, were suitable for the synthesis of ruthenium amidinate compounds with quite good yields.

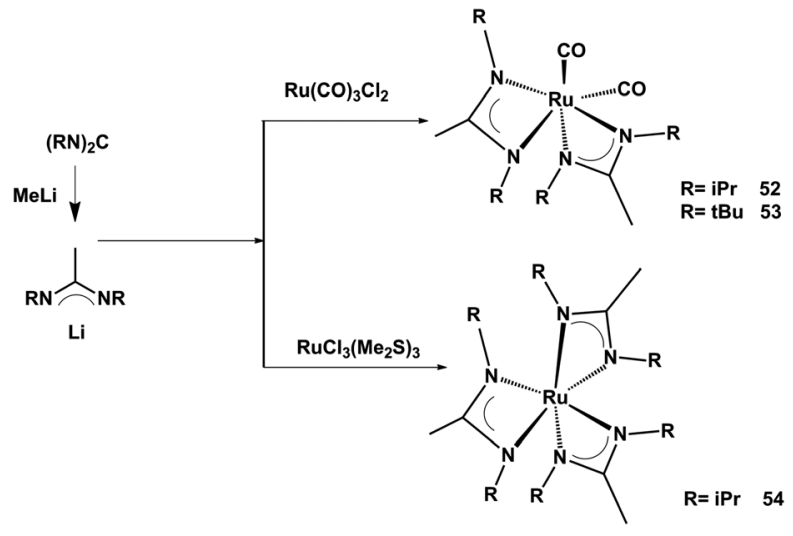

Scheme 15 Synthesis of Ru amidinate 52-54. Adapted from ref. 149.
Table 4 Physical properties of complexes 52-54. Source ref. 137

\begin{tabular}{lllll}
\hline & $\begin{array}{l}\text { Vapor pressure } \\
\left({ }^{\circ} \mathrm{C} / \text { Torr }\right)\end{array}$ & M.P. ${ }^{\circ} \mathrm{C}$ & Color & $T_{1 / 2}(\mathrm{~h})$ \\
\hline $\mathbf{5 2}$ & $85 / 0.05$ & $>250$ & Blue & 15 \\
$\mathbf{5 3}$ & $50 / 0.045$ & 122 & Yellow & $\mathrm{n} / \mathrm{a}$ \\
$\mathbf{5 4}$ & $130 / 0.055$ & 204 & Pale yellow & 44 \\
\hline
\end{tabular}

These compounds owing to the formation of a $\mathrm{Ru}-\mathrm{N}$ bond, are found to be reactive towards hydrogen (forming $\mathrm{Ru}$ ), water (forming oxide) and ammonia (forming nitrides) with minimal impurities of carbon and oxygen in the deposited films. However, complexes containing $\mathrm{Ru}-\mathrm{C}$ bonds lack a sufficient reactivity with hydrogen, water and ammonia. ${ }^{148}$ Thus, in general, the advantages of the metal amidinate precursors include sufficient volatility, low deposition temperature, high thermal stability and good quality of the formed films. The physical characteristics of these newly synthesized compounds 52-54 are listed in a Table 4.

\section{(d) Miscellaneous ruthenium CVD precursors}

As mentioned earlier, Ru thin film deposition often follows a Volmer-Weber growth mechanism. Due to the high surface energy and due to much faster diffusion at grain boundaries this leads to polycrystalline, columnar films. ${ }^{150}$ For a good microstructure of $\mathrm{Ru}$ films, an improvement in the barrier properties are essential. ${ }^{151}$ As changing the Ru film microstructure from polycrystalline to nanocrystalline should eliminate or suppress the fast diffusion through grain boundaries and increase the film nucleation and deposition rate. It is also believed that the choice of precursors and reaction conditions can strongly influence both, the composition and the size of thin film. In this context, some other precursors including other atoms which may lead to the formation of Ru containing films in CVD will be discussed here.

Huang et al. reported ${ }^{152}$ a mixed Pt-Ru complex $\left[\mathrm{CpRu}\left(\eta^{5}-\right.\right.$ $\mathrm{C}_{5} \mathrm{H}_{3} \mathrm{CH}_{2} \mathrm{NMe}_{2}$ ) $\left.\mathrm{Pt}(\mathrm{DMSO}) \mathrm{Cl}\right] \mathbf{5 5}$ which is highly volatile. The deposition of thin films from this compound at lower temperature leads to highly dispersed Pt-Ru binary alloys. However, the phase separation of the initially homogenous $\mathrm{Pt}-\mathrm{Ru}$ was observed upon raising the temperature to $400{ }^{\circ} \mathrm{C}$ (Scheme 16).

Kang et al. also reported Pt-doped Ru thin films using cyclopentadienyl-propylcyclopentadienlylruthenium(II) and (trimethyl)methylcyclo pentadienlylplatinum(Iv) $\mathbf{5 6}$ as the $\mathrm{Ru}$ and Pt CVD precursors (Fig. 20). ${ }^{74}$

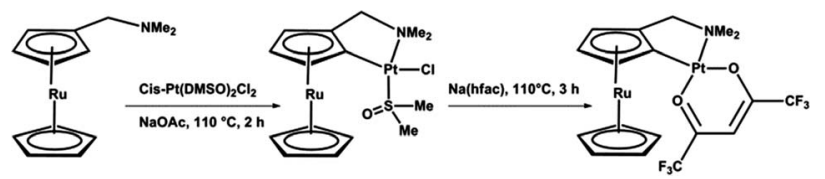

Scheme 16 Synthetic strategy of [CpRu( $\left.\eta^{5}-\mathrm{C}_{5} \mathrm{H}_{3} \mathrm{CH}_{2} \mathrm{NMe}_{2}\right) \mathrm{Pt}(\mathrm{DMSO})$ Cl] 55. Adapted from ref. 152. 


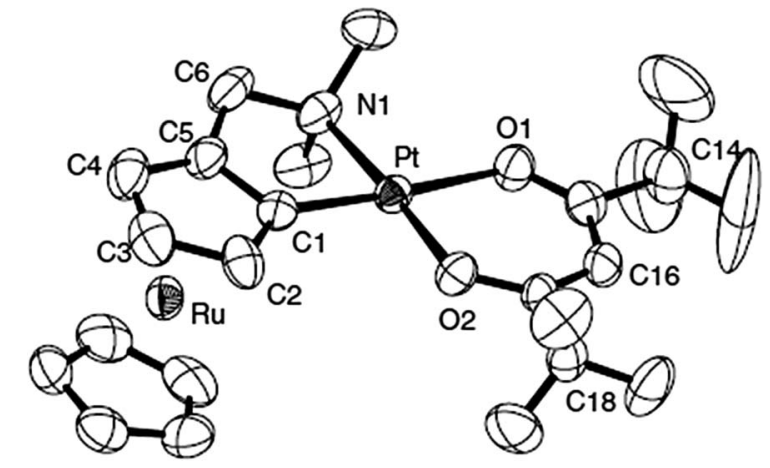

Fig. 20 Crystal structure of $\left[\mathrm{CpRu}\left(\eta^{5}-\mathrm{C}_{5} \mathrm{H}_{3} \mathrm{CH}_{2} \mathrm{NMe}_{2}\right) \mathrm{Pt}(\mathrm{DMSO}) \mathrm{Cl}\right]$ depicting the binding mode. Source ref. 152

In 2006, Shin et al. ${ }^{153}$ explored highly conformal, smooth films of amorphous ruthenium-phosphorus alloy (RuP) using cis- $\mathrm{H}_{2} \mathrm{Ru}\left(\mathrm{PMe}_{3}\right)_{4}\left(\mathrm{Me}=\mathrm{CH}_{3}\right)$ which contains $\mathrm{Ru}-\mathrm{H}$ and $\mathrm{Ru}-\mathrm{P}$ bonds. The CVD process depends on the ligand selection: In cis$\mathrm{H}_{2} \mathrm{Ru}\left(\mathrm{PMe}_{3}\right)_{4} 57$, the $\mathrm{PMe}_{3}$ ligands is a highly volatile leaving group whereas the $\mathrm{Ru}-\mathrm{H}$ bond facilitate a dissociative adsorption. Growth of highly conformal, smooth films of amorphous RuP alloys were formed after the complete demethylation of $\mathrm{PMe}_{3}$ on $\mathrm{Ru}(0001)$ at $500 \mathrm{~K}$. The chemical composition of this precursor has a direct influence on both the elemental composition and morphology of the grown films. A further detailed study of this precursor ${ }^{154}$ describes that the films remain amorphous even upon heating for $3 \mathrm{~h}$ at $635 \mathrm{~K}$, and only begin to crystallize upon annealing at $775 \mathrm{~K}$ for $30 \mathrm{~min}$ in vacuum. Furthermore, it is believed that heteroatom incorporation interferes with crystallite formation, since the as-deposited films are X-ray amorphous showing no long range order. Further McCarty et al. ${ }^{155}$ extended this concept and prepared some new ruthenium phosphite hydride complexes $\mathrm{H}_{2} \mathrm{Ru}\left(\mathrm{P}(\mathrm{OR})_{3}\right)_{4}(\mathrm{R}=$ Me 58, Et 59 or iPr 60) in order to determine the possible effects of precursor ligand chemistry on film morphology and composition. The incorporation of trialkylphosphite $\left(\mathrm{P}(\mathrm{OR})_{3}\right)$ over trialkyl phosphine as they are more air stable and less expensive. The composition of the films was

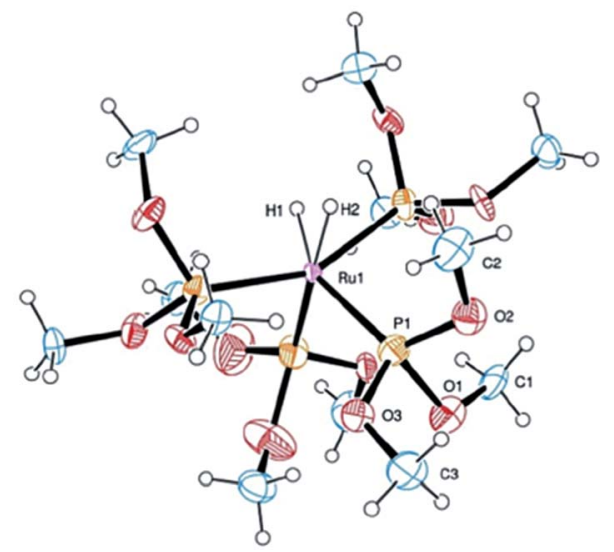

Fig. 21 Crystal structure of $\left[\mathrm{H}_{2} \mathrm{Ru}\left(\mathrm{P}(\mathrm{OMe})_{3}\right)_{4}\right]$. Source ref. 155. found to depend on the ligand chemistry as well as on the deposition conditions. The use of $\mathrm{H}_{2}$ as the carrier gas had the effect of increasing the relative concentrations of $\mathrm{P}$ and $\mathrm{O}$ for all films. The crystal structure of $\left[\mathrm{H}_{2} \mathrm{Ru}\left(\mathrm{P}(\mathrm{OMe})_{3}\right)_{4}\right]$ is depicted in Fig. 21.

In the formation of ruthenium thin films, mainly carbon impurities have been present owing to insufficient oxidant supply during the deposition process. The co-deposited C may hinder the grain growth of metal particles, resulting in the formation of nanoparticle with significantly large surface area. For utilization of this property in 2007, Sakata et al. ${ }^{\mathbf{1 5 6}}$ reported ruthenium-carbon ( $\mathrm{Ru}-\mathrm{C})$ nano-composite films which were prepared by plasma-enhanced chemical vapor deposition (PECVD) in the presence of Ar gas using $\left[\mathrm{Ru}(\mathrm{dpm})_{3}\right]$ or $\left[\mathrm{Ru}(\mathrm{tmhd})_{3}\right]$ (dipivaloylmethanate) $\mathbf{6 1}$ as ruthenium precursors (Fig. 22). Ruthenium thin films were formed as (10 to $20 \mathrm{~nm}$ ) agglomerated grains with 2.5 to $3.5 \mathrm{~nm}$ of $\mathrm{Ru}$ particles in a carbon matrix. The interfacial electrical conductivity is calculated $0.2 \times 10^{-3} \mathrm{~S} \mathrm{~m}^{-1}$ at the $\mathrm{Ru}-\mathrm{C} / \mathrm{YSZ}$ interface (Ru-yttriastabilized zirconia solid electrolyte) at $500 \mathrm{~K}$.

Li et al. ${ }^{157}$ also explored a single source precursor heteronuclear carbonyl cluster $\left[\operatorname{RuOs}_{3}(\mathrm{CO})_{13}\left(\mu-\mathrm{H}_{2}\right] 62\right.$ for the preparation of thin films of Os-Ru binary alloy. The ratio of osmium to ruthenium varied with the deposition temperature, and at higher temperatures $\left(400-500{ }^{\circ} \mathrm{C}\right)$ the deposited surface was smoother. The structure of the cluster represented in Fig. 23.

Recently Popovska et al. prepared carbon nanotubes by catalytic chemical vapor deposition (CCVD) with the help of iron, ruthenium and bimetallic $\mathrm{Fe} / \mathrm{Ru}$ nanoparticles on spNaY zeolite support and acetylene as the carbon source. ${ }^{158}$ The nanoparticle catalysts $\mathbf{6 3}$ were prepared by fluidized bed metal organic chemical vapor deposition (FB-MOCVD) using ruthenium precursor [(benzene)(1,3-cyclohexadiene) $\mathrm{Ru}(0)]$ and form CNTs with low 0.05 wt $\% \mathrm{Ru}$ concentrations. The crystalline solid ruthenium thin film deposition occurs as the formation of metal nanoparticles at oxidic surfaces. The deposition scheme is presented in Scheme 17.

In 2011, Bouanis et al. reported single-walled carbon nanotubes (SWCNTs) growth on Ru nanoparticle catalyst 64

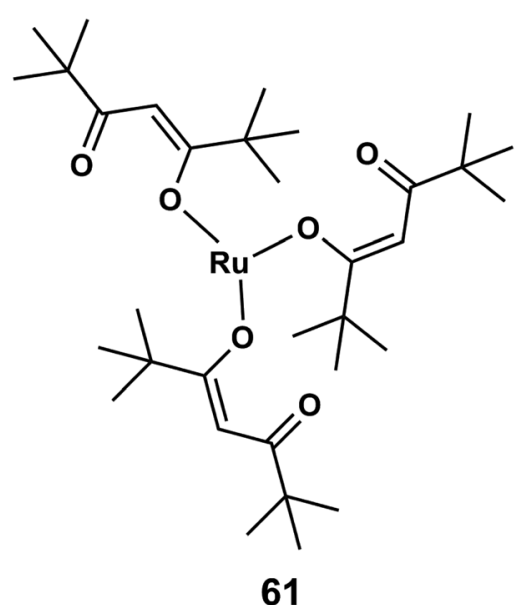

Fig. 22 Structure of dipivaloylmethanate ruthenium or $\mathrm{Ru}(\mathrm{tmhd})_{3}$. 


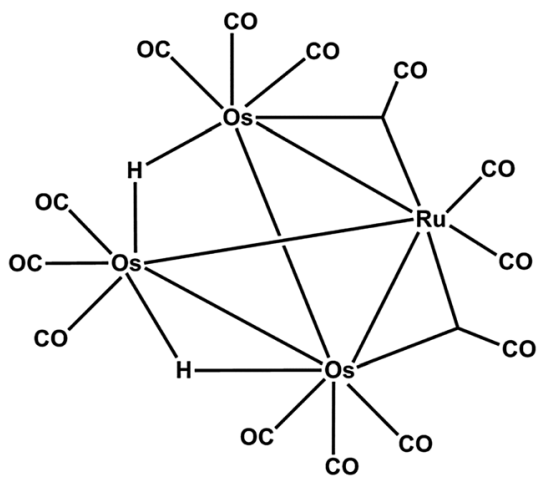

Fig. 23 Molecular structure of mixed Os-Ru carbonyl cluster 62.

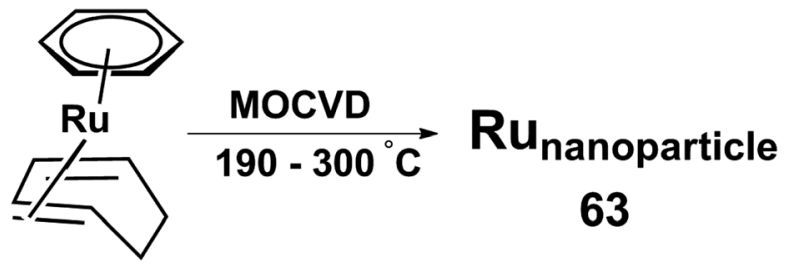

Scheme 17 [(Arene)(diene)Ru(0)] 63 metal organic precursor complexes used for the metal catalysts deposition. Adapted from ref. 158 .

synthesized by RuTTP complex (5,10,15,20-tetraphenyl$21 H, 23 H$-porphine ruthenium(II)) via chemical vapor deposition as represented in Fig. $24 .^{159}$ Self assembled monolayers of Ru tetraphenyl porphyrins (RuTPP) were used as catalyst on the $\mathrm{SiO}_{2} / \mathrm{Si}(100)$ growth substrates pre-functionalized by silanization to form a pyridine terminated molecular monolayer by HFCVD (hot filament CVD).

Recently, nanoparticles from dodecatriruthenium dodecacarbonyl $\mathrm{Ru}_{3}(\mathrm{CO})_{12} 65$ were also explored for ruthenium deposition on $\mathrm{SiO}_{2} / \mathrm{Si}(001)$ substrates at $473 \mathrm{~K}$ with and without an overpressure of CO by Liao et al. ${ }^{160}$ A highly smooth thin film is obtained by carbon monoxide addition during growth. The reaction kinetics showed that the addition of $\mathrm{CO}$ to the reaction,

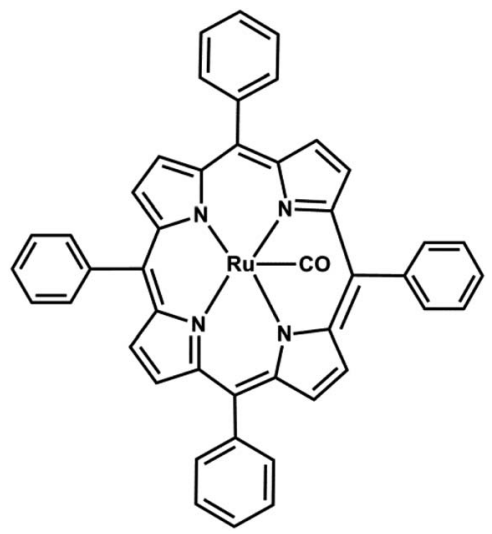

Fig. 24 Structure of 5,10,15,20-tetraphenyl-21H,23H-porphine ruthenium(II) carbonyl 64.

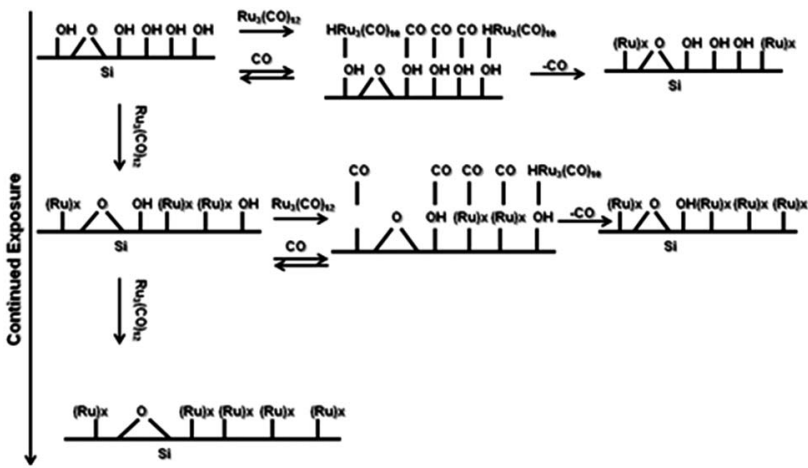

Fig. 25 Schematic diagram of CO addition to Ru CVD at different times as compared to deposition without CO. Adapted from ref. 160.

chamber reduces the $\mathrm{Ru}$ nanoparticle density by limiting the $\mathrm{Ru}$ adatom formation at hydroxyl sites as depicted in Fig. 25. The gas $\mathrm{CO}$ also adsorbs on the surface of $\mathrm{Ru}$ nanoparticles and facilitates the ruthenium island formation. The addition of CO with proper timing and effective partial pressure decreases the film growth rate, surface roughness, and nanocrystalline grain growth. Carbon monoxide was employed to inhibit the growth of previously nucleated islands to allow the formation of additional nuclei. After inhibition of growth, previously nucleated islands of ruthenium allow the formation of additional nuclei. The CO blocks the free hydroxyls present on the silica substrate where the Ru precursor adsorption and decomposition occurs. After two hours, thinner and smoother ruthenium thin films were obtained compared to a deposition without CO for $10 \mathrm{~min}$ because $\mathrm{CO}$ adsorption on the Ru surface slows the $\mathrm{Ru}$ island growth rate.

In summary, an introduction of $\mathrm{F}$ over $\mathrm{H}$ on diketonate and pyrazolate ruthenium precursors increases the volatility leading to the formation of thin film layer formation. However, carboxyl groups bearing ruthenocene complexes show a higher volatility compared to the corresponding ruthenocenes. Introduction of trimethyl silyl groups in organometallic ruthenium precursors also induces both, higher vapor pressures and lower melting points. As compared to [(benzene)(1,3-cyclohexadiene) $\mathrm{Ru}(0)]$, its alkyl substituted derivatives also improves the CVD properties.

\section{Conclusion}

In this review, we have discussed a variety of ruthenium precursors for chemical vapor deposition that have been reported in last few years. Exciting progress has been made during the past few decades in the synthesis and electronic applications of ruthenium precursors to form pure films using developed methodology and have been attempted to present an up-to-date overview of this rapidly growing field of research. For those unfamiliar with CVD, a brief introduction of the CVD technique and significant applications of CVD films are given. The examples collected in the present review focus mainly on ruthenium based organometallics, carbonyls, diketonates and nitrogen containing derivatives. It is observed that small 
changes in the ligand frame work in the periphery of ruthenium precursors can significantly influence properties which in turn can have a distinct effects in the properties of the deposited thin films. Mainly different bond strengths of $\mathrm{C}-\mathrm{H}$ and $\mathrm{C}-\mathrm{C}$ bond compared to $\mathrm{Ru}-\mathrm{C}$ or $\mathrm{Ru}-\mathrm{O}$ bonds are important regarding the decomposition pathways and temperature regimes for CVD. These properties also directly influence the carbon contamination within the films. Further improvements seem possible here, also including theoretical evaluation methods to estimate bond strengths in designed precursors prior to their synthesis. But theory, in general, cannot provide good estimates regarding vapor pressures, while reasonably high vapor pressures are a crucial prerequisite for CVD. At the end careful experiments will be needed to investigate the difference of evaporation temperature and deposition temperature of a given precursor.

The properties of the deposited films are intrinsically coupled to the properties of the precursors, thus further progress regarding typical properties like specific conductivity can be expected with improved precursor design. As seen, quite often a compromise must be found between the desired precursor and film properties and the price of the precursors, and thus of the production. Many material chemists are actively involved in this promising field, and hence, the synthesis of new highly efficient and advanced ruthenium precursors for CVD is still demanding.

\section{Acknowledgements}

Authors (LM, RG) gratefully acknowledge INSA-DFG and CSIR New Delhi, India for their financial assistance.

\section{References}

1 E. Kondoh, Jpn. J. Appl. Phys., 2005, 44, 5799-5802.

2 G. C. Bond and J. C. Slaa, J. Mol. Catal. A: Chem., 1995, 101, 243-253.

3 P. Jakob and D. Menzel, Surf. Sci., 1988, 210(3), 503-530.

4 M. C. Sanchez Sierra, J. García Ruiz, M. G. Proietti and J. Blasco, J. Mol. Catal. A: Chem., 1995, 96, 65-75.

5 J. U. Köhler and H. L. Krauss, J. Mol. Catal. A: Chem., 1997, 123, 49-64.

6 A. Schneider, N. Popovska, I. Jipa, B. Atakan, M. A. Siddiqi, R. Siddiqui and U. Zenneck, Chem. Vap. Deposition, 2007, 3, 389-395, and references therein.

7 K. Gregorczyk, L. Henn-Lecordier, J. Gatineau, C. Dussarrat and G. Rubloff, Chem. Mater., 2011, 23, 2650-2656.

8 T. Kawahara, M. Yamamuka, A. Yuuki and K. Ono, Jpn. J. Appl. Phys., 1996, 35, 4880-4885.

9 A. Tsuzumitani, Y. Okuno, J. Shibata, T. Shimizu, K. Yamamoto and Y. Mori, Jpn. J. Appl. Phys., 2000, 39, 2073-2077.

10 N. Inoue, N. Furutake, A. Toda, M. Tada and Y. Hayashi, IEEE Trans. Electron Devices, 2005, 52(10), 2227-2235.

11 T. Furukawa, T. Kuroiwa, Y. Fujisaki, T. Sato and H. Ishiwara, Jpn. J. Appl. Phys., 2005, 44, L378-L380.

12 D. Bekermann, D. Barreca, A. Gasparotto and C. Maccato, CrystEngComm, 2012, 14, 6347-6358.
13 M. Damayanti, T. Sritharan, Z. H. Gan, S. G. Mhaisalkar, N. Jiang and L. Chan, J. Electrochem. Soc., 2006, 153, J41$\mathrm{J} 45$.

14 M. S. Mudholkar and L. T. Thompson, J. Appl. Phys., 1995, 77, 5138.

15 G. R. Harp and S. S. P. Parkin, Thin Solid Films, 1996, 288, 315-324.

16 R. Triboulet and J. Perriere, Prog. Cryst. Growth Charact. Mater., 2003, 47, 65-138.

17 P. S. Patil, E. A. Ennaoui, C. D. Lokhande, M. Müller, M. Giersig, K. Diesner and H. Tributsch, Thin Solid Films, 1997, 310, 57-62.

18 Q. X. Xia, X. D. Wu, G. Song and S. R. Foltyn, J. Vac. Sci. Technol., A, 1996, 14, 1107-1111.

19 Y. Gao, G. Bai, Y. Liang, G. C. Dunham and S. A. Chambers, J. Mater. Res., 1997, 12, 1844-1849.

20 I. Zhitomirsky, Mater. Lett., 1998, 33, 305-310.

21 K. Kameyama, S. Shohji, S. Onoue, K. Nishimura, K. Yahikozawa and Y. Takasu, J. Electrochem. Soc., 1993, 140, 1034-1037.

22 J. R. V. Gracia and T. Goto, Mater. Trans., 2003, 44, 17171728.

23 D.-J. Lee, S.-W. Kang and S.-W. Rhee, Thin Solid Films, 2002, 413, 237-242.

24 J. Sankar, T. K. Sham and R. J. Puddephatt, J. Mater. Chem., 1999, 9, 2439-2444.

25 B. Borca, S. Barja, M. Garnic, M. Minniti, A. Politano, J. M. Rodriguez-García, J. J. Hinarejos, D. Farías, A. L. V. de Parga and R. Miranda, New J. Phys., 2010, 12, 093018-093035.

26 A. Politano, D. Campi, V. Formosoac and G. Chiarello, Phys. Chem. Chem. Phys., 2013, 15, 11356-11361.

27 A. Politano and G. Chiarello, Carbon, 2013, 61, 412-417.

28 W. Feng, S. Lei, Q. Li and A. Zhao, J. Phys. Chem. C, 2011, 115, 24858-24864.

29 E. Sutter, P. Albrecht and P. Sutter, Appl. Phys. Lett., 2010, 97, 213101.

30 E. Sutter, P. Albrecht and P. Sutter, Appl. Phys. Lett., 2010, 97, 213101.

31 E. Sutter, P. Albrecht and P. Sutter, Appl. Phys. Lett., 2009, 95, 133109.

32 A. Politano, B. Borca, M. Minniti, J. J. Hinarejos, A. L. Vázquez de Parga, D. Farías and R. Miranda, Phys. Rev. B: Condens. Matter Mater. Phys., 2011, 84, 035450.

33 B. Holst and W. Allison, Nature, 1997, 390, 244.

34 A. Politano and G. Chiarello, Appl. Phys. Lett., 2013, 102, 201608.

35 A. Politano and G. Chiarello, Nanoscale, 2013, 5, 8215.

36 H. Yan, X. Li, B. Chandra, G. Tulevski, Y. Wu, M. Freitag, W. Zhu, P. Avouris and F. Xia, Nat. Nanotechnol., 2012, 7, 330.

37 M. Schwander and K. Partes, Diamond Relat. Mater., 2011, 20, 1287-1301.

38 J. R. Creighton and P. Ho, Introduction to Chemical vapor Deposition (CVD), in Chemical Vapor Deposition, ed. J. H. Park and T. S. Sudarshan, ASM International, Materials Park, OH, 2001. 
39 Chemical vapor deposition (Surface engineering series), ed. J. H. Park and T. S. Sudarshan, ASM International, 2001.

40 U. Bergmann, K. Lummer, B. Atakan and K. KohseHöinghaus, Ber. Bunsen-Ges., 1998, 102(7), 906-914.

41 Thin Film Processes, ed. John L. Vossen and Werner Kern, academic press inc (Landon) Ltd., 1978, pp. 73-3348.

42 U. Bergmann, V. Reimer and B. Atakan, Phys. Chem. Chem. Phys., 1999, 1(24), 5593-5599.

43 T. Haase, K. Kohse-Höinghaus, B. Atakan, H. Schmidt and H. Lang, Chem. Vap. Deposition, 2003, 9(3), 144-148.

44 A. C. Jones and P. O'Brien, General Materials Science, C[VD of Compound Semiconductors: Precursor Synthesis, Developmeny and Applications, 2008, pp. 1-352.

45 C. A. D. Dion and J. R. Tavares, Powder Technol., 2013, 239, 484-491.

46 W. Kern and V. Ban in Chemical Vapor Deposition of Inorganic Thin Films, ed. John L. Vossen and Werner Kern, Academic Press, 1978, pp. 257-331, and references there in.

47 D. W. Hess, K. F. Jensen and T. J. Anderson, Rev. Chem. Eng., 1985, 3, 99-176 and references there in.

48 C. Pflitsch, D. Viefhaus, U. Bergmann, V. Kravets, H. Nienhaus and B. Atakan, J. Electrochem. Soc., 2006, 153(8), C546-C550.

49 G. D. Papasouliotis and S. V. Sotirchos, J. Mater. Res., 1999, 14(8), 3397-3409.

50 D. W. Shaw, J. Cryst. Growth, 1975, 31, 130.

51 Y. Kangawa, T. Akiyama, T. Ito, K. Shiraishi and T. Nakayama, Materials, 2013, 6, 3309-3361.

52 T. Hur'yeva, M. Lisker and E. P. Burte, Chem. Vap. Deposition, 2006, 12, 429-434.

53 P. Hones, F. Lévy, T. Gerfin and M. Grätzel, Chem. Vap. Deposition, 2000, 6(4), 193-198.

54 L. Liu, H. Zhou, R. Cheng, Y. Chen, Y.-C. Lin, Y. Qu, J. Bai, I. A. Ivanov, G. Liu, Y. Huang and X. Duan, J. Mater. Chem., 2012, 22, 1498-1503.

55 R. A. Levy, J. M. Grow and G. S. Chakravarthy, Chem. Mater., 1993, 5(12), 1710-1714.

56 G. Luo, P. Zhu, P. Chen, Z. Liu, H. Lin and P. Qian, Vacuum, 2000, 59, 927-931.

57 H. O. Pierson, Handbook of chemical vapor deposition, Park Ridge, Noyes, 1992.

58 M. L. Hitchman and A. C. Jones, Chemical Vapor Deposition: Precursors, Processes and Applications, 2009; M. L. Hitchman and A. C. Jones, Chemical Vapor Deposition: Principles and Applications, Academic Press, 1993.

59 J. Tavares, E. J. Swanson and S. Coulombe, Plasma Processes Polym., 2008, 5(8), 759-769 and references there in.

60 G. Wahl, P. B. Davies, R. F. Bunshah, B. A. Joyce, C. D. Bain, G. Wegner, M. Remmers, F. C. Walsh, K. Hieber, J.-E. Sundgren, P. K. Bachmann, S. Miyazawa, A. Thelen, H. Strathmann and K. J. Edler, Ullmann's Encyclopedia of Industrial Chemistry, 2014, pp. 1-75.

61 E. H. A. Granneman, Thin Solid Films, 1993, 228, 1-11.

62 G. Kalita, M. S. Kayastha, H. Uchida, K. Wakitaa and M. Umenoa, RSC Adv., 2012, 2, 3225-3230.

63 V. Shanov, W. Tabakoff and R. N. Singh, J. Mater. Eng. Perform., 2002, 11, 220-225.
64 R. Bogdanowicz, M. Smietana, M. Gnyba, M. Ficek, V. Stranák, Ł. Golunski, M. Sobaszek and J. Ryl, Phys. Status Solidi A, 2013, 1-7.

65 P. Török and F.-J. Kao, J. Raman Spectrosc., 2006, 37, 956957.

66 T. G. Brown, Optical Fibers and Fiber-Optic Communications, in Handbook of Optics, ed. M. Bass, McGraw-Hill, New York, 2nd edn, 1995, Vol. II.

67 T. J. Cervantes, L. T. Romano and M. A. Kneissl, US 6379985 B1, 2002.

68 D. T. Read and A. A. Volinsky, Micro- and opto-electronic materials and structures: Physics, mechanics, design, reliability, packaging, ed. E. Suhir, et al, Springer, New York, 2007, vol. 1, pp. 135-180.

69 R. Dhansekaran and P. Ramasamy, Indian J. Eng. Mater. Sci., 2000, 7, 350-353.

70 J. A. Venables and G. L. price, in Epitaxial Growth, ed. J. W. Matthew, Academic Press, 1975, part B, p. 382.

71 D. King and D. Woodruff, Growth and Properties of ultra thin Epitaxial Layers, Elsevier, 1997.

72 J. Shin, A. Waheed, K. Agapiou, W. A. Winkenwerder, H.-W. Kim, R. A. Jones, G. S. Hwang and J. G. Ekerdt, J. Am. Chem. Soc., 2006, 128, 16510-16511.

73 G. B. Stringfellow, J. Cryst. Growth, 1984, 68, 111-120.

74 S. Y. Kang, C. S. Hwang and H. J. Kim, J. Electrochem. Soc., 2005, 152(1), C15-C19 and references there in.

75 L. McElwee-White, Dalton Trans., 2006, 5327-5333.

76 D. H. Jang and J. S. Chun, J. Vac. Sci. Technol., A, 1989, 7(1), 31-35.

77 A. C. Jones, J. Mater. Chem., 2002, 12, 2576-2590.

78 T. Y. Chou, Y. H. Lai, Y. L. Chen, Y. Chi, K. R. Prasad, A. J. Carty, S. M. Peng and G. H. Lee, Chem. Vap. Deposition, 2004, 10, 149-158.

79 K. C. Smith, Y.-M. Sun, N. R. Mettlach, R. L. Hance and J. M. White, Thin Solid Films, 2000, 376, 73-81.

80 P. C. Liao, Y. S. Huang and K. K. Tiong, J. Alloys Compd., 2001, 98, 317-318.

81 M. A. Siddiqi and B. Atakan, Thermochim. Acta, 2007, 452, 128-134.

82 Y. Chi, S. Ranjan, P.-W. Chung, C.-S. Liu, S. M. Peng and G.-H. Lee, J. Chem. Soc., Dalton Trans., 2000, 343-347.

83 B. D. Fahlman and A. R. Barron, Adv. Mater. Opt. Electron., 2000, 10, 223-232.

84 E. I. Tsyganova and L. M. Dyagileva, Russ. Chem. Rev., 1996, 65(4), 315-328 and references there in.

85 G. G. Condorelli, G. Malandrino and I. L. Fragal, Coord. Chem. Rev., 2007, 251, 1931-1950.

86 Z. Yuan, R. J. Puddephatt and M. Sayer, Chem. Mater., 1993, 5, 908-910.

87 S. E. Park, H. M. Kim, K. B. Kim and S. H. Min, J. Electrochem. Soc., 2000, 147(1), 203-209 references therein.

88 A. D. Berry, D. J. Brown, R. Kaplan and E. J. Cukauskas, J. Vac. Sci. Technol., A, 1986, 4, 215-218.

89 A. Z. Rubezhov, Platinum Met. Rev., 1992, 36, 26-33 and references there in.

90 Q. Wang, J. G. Ekerdt, D. Gay, Y.-M. Sun and J. M. White, Appl. Phys. Lett., 2004, 84(8), 1380-1382. 
91 Y. Senzaki, F. B. McCormick and W. L. Gladfelter, Chem. Mater., 1992, 4, 747-749.

92 T. Aaltonen, M. Ritala, K. Arstila, J. Keinonen and M. Leskelä, Chem. Vap. Deposition, 2004, 10, 215-219.

93 L. Wolf, E. Butter and H. Weinelt, Z. Anorg. Allg. Chem., 1960, 306, 87-93.

94 D. Rose and G. Wilkinson, J. Chem. Soc. A, 1970, 1791-1795. 95 A. F. Bykov, N. B. Morozova, I. K. Igumenov and S. V. Sysoev, J. Therm.Anal., 1996, 46, 1551-1565 and references there in.

96 M. Lashdaf, T. hatanpaa and M. Titta, J. Therm. Anal. Calorim., 2001, 64, 1171-1182.

97 N. B. Morozova, G. I. Zharkova, P. P. Semyannikov, S. V. Sysoev, I. K. Igumenov, N. E. Fedotova and N. V. Gelfond, J. Phys. IV, 2001, 11, 609-616.

98 M. A. R. D. Silva and M. L. C. C. H. Ferrao, Pure Appl. Chem., 1888, 60, 1225-1234 and references there in.

99 M. L. Green, M. E. Gross, L. E. Papa, K. J. Schnoes and D. Brasen, J. Electrochem. Soc., 1985, 132, 2677-2685.

100 A. F. Bikov, N. B. Morozova, I. K. Igumenov and S. V. Sysoev, J. Therm. Anal., 1996, 46, 1551-1565.

101 W. L. M. Weerts, M. H. J. M. de Croon and G. B. Marin, J. Electrochem. Soc., 1997, 144, 3213.

102 V. Y. Vasilyev, K. P. Mogilnikov and Y. W. Song, Electrochem. Solid-State Lett., 2008, 11(12), D89-D93.

103 V. Y. Vasilyev, K. P. Mogilnikov and Y. W. Song, Curr. Appl. Phys., 2009, 9, e148-e151.

104 V. Y. Vasilyev, Russ. Microelectron., 2010, 39, 262-272.

105 J. M. Lee, J. C. Shin, C. S. Hwang, H. J. Kim and C.-G. Suk, J. Vac. Sci. Technol., A, 1998, 16(5), 2768-2771.

106 G.-R. Bai, A. Wang, C. M. Foster and J. Vetrone, Thin Solid Films, 1997, 310, 75-80.

107 F.-J. Lee, Y. Chi, C.-S. Liu, P.-F. Hsu, T.-Y. Chou, S.-M. Peng and G.-H. Lee, Chem. Vap. Deposition, 2001, 7(3), 99-101.

108 Y.-H. Lai, Y.-L. Chen, Y. Chi, C.-S. Liu, A. J. Carty, S.-M. Pengc and G.-H. Lee, J. Mater. Chem., 2003, 13, 1999-2006.

109 W.-Y. Cheng, L.-S. Honga, J.-C. Jianga, Y. Chib and C.-C. Lin, Thin Solid Films, 2005, 483, 31-37.

110 H. Z. Yu and C. V. Thompson, Acta Mater., 2014, 67, 189198.

111 Y.-H. Lai, T.-Y. Chou, Y.-H. Song, C.-S. Liu, Y. Chi, A. J. Carty, S.-M. Peng and G.-H. Lee, Chem. Mater., 2003, 15, 2454-2462.

112 Y. Chi, P.-F. Hsu, C.-S. Liu, W.-L. Ching, T.-Y. Chou, A. J. Carty, S.-M. Peng, G.-H. Lee and S.-H. Chuang, J. Mater. Chem., 2002, 12, 3541-3550.

113 Y.-L. Chen, C.-S. Liu, Y. Chi, A. J. Carty, S.-M. Peng and G.-H. Lee, Chem. Vap. Deposition, 2002, 8, 17-20.

114 Y. Chi, F. J. Lee and C.-S. Liu, US6303809 B1, 2001.

115 D. Morquardt, J. Barthel, M. Braun, C. Ganter and C. Janiak, CrystEngComm, 2012, 14, 7607-7615 and references there in.

116 T. Aoyama and K. Eguchi, Jpn. J. Appl. Phys., 1999, 38(10A), L1134-L1136.

117 S. Y. Kang, K. H. Choi, S. K. Lee, C. S. Hwang and H. J. Kim, J. Electrochem. Soc., 2000, 147(3), 1161-1167.

118 G. Wilkinson, J. Am. Chem. Soc., 1952, 74, 6146-6147.
119 D. E. Bublitz, W. E. McEwen and J. Kleinberg, Org. Synth., 1973, 5, 1001.

120 D. E. Trent, B. Paris and H. H. Krause, Inorg. Chem., 1964, 3(7), 1057-1058.

121 T. Aoyama and K. Eguchi, Jpn. J. Appl. Phys., 1999, 38, L1134-L1136.

122 Y. Matsui, M. Hiratani, T. Nabatame, Y. Shimamoto and S. Kimura, Electrochem. Solid-State Lett., 2002, 5(1), C18C21.

123 M. Kadoshima, T. Nabatame, M. Hiratani, Y. Nakamura, I. Asano and T. Suzuki, Jpn. J. Appl. Phys., 2002, 41(3B), L347-L350.

124 T. Nabatame, M. Hiratani, M. Kadoshima, Y. Shimamoto, Y. Matsui, Y. Ohji, I. Asano, T. Fujiwara and T. Suzuki, Jpn. J. Appl. Phys., 2000, 39(11B), L1188-L1190.

125 J. J. Kim, D. H. Jungb, M. S. Kim, S. H. Kim and D. Y. Yoon, Thin Solid Films, 2002, 409, 28-32.

126 S. Y. Kang, H. J. Lim, C. S. Hwang and H. J. Kim, J. Electrochem. Soc., 2002, 149(6), C317-C323.

127 D. Gan, P. S. Ho, Y. Pang, R. Huang, J. Leu, J. Maiz and T. Scherban, J. Mater. Res., 2006, 21(6), 1512-1518.

128 M. A. Siddiqi, R. A. Siddiqui, B. Atakan, N. Roth and H. Lang, Materials, 2010, 3, 1172-1185.

129 W. Trakarnpruk, A. M. Arif and R. D. Ernst, Organometallics, 1992, 11, 1686-1692.

130 A. Tuchscherer, C. Georgi, N. Roth, D. Schaarschmidt, T. Rüffer, T. Waechtler, S. E. Schulz, S. Oswald, T. Gessner and H. Lang, Eur. J. Inorg. Chem., 2012, 48674876.

131 J. Choi, Y. Choi, J. Hong, H. Tian, J.-S. Roh, Y. Kim, T.-M. Chung, Y. W. Oh, Y. Kim, C. G. Kim and K. No, Jpn. J. Appl. Phys., 2002, 41, 6852-6856.

132 I. Jipa, K. Danova, N. Popovska, M. A. Siddiqi, R. A. Siddiqui, B. Atakan, T. Cremer, F. Maier, H. Marbach, H.-P. Steinrück, F. W. Heinemann and U. Zenneck, J. Mater. Chem., 2011, 21, 3014-3024.

133 I. Jipa, K. Danova, N. Popovska, M. A. Siddiqi, R. A. Siddiqui, B. Atakan, T. Cremer, F. Maier, H. Marbach, H.-P. Steinrück, F. W. Heinemann and U. Zenneck, J. Mater. Chem., 2011, 21, 3014-3024.

134 A. Schneider, N. Propovska, F. Holzmann, H. Gerhard, C. Topf and U. Zenneck, Chem. Vap. Deposition, 2005, 11, 99-105.

135 I. Jipa, M. A. Siddiqi, R. A. Siddiqui, B. Atakan, H. Marbach, T. Cremer, F. Maier, H.-P. Steinrück, K. Danova, N. Popovska, F. W. Heinemann and U. Zenneck, Chem. Vap. Deposition, 2011, 17, 15-21.

136 K. Kawano, H. Kosuge, N. Oshima and H. Funakubo, Electrochem. Solid-State Lett., 2007, 10(6), D60-D62.

137 K. C. Smitha, Y.-M. Suna, N. R. Mettlacha, R. L. Hanceb and J. M. White, Thin Solid Films, 2000, 376, 73-81.

138 J.-H. Lee, J.-Y. Kim, S.-W. Rhee, D. Y. Yang, D.-H. Kim, C. -H. Yang, Y.-K. Han and C.-J. Hwang, J. Vac. Sci. Technol., A, 2000, 18(5), 2400-2403.

139 J.-H. Lee, J.-Y. Kim and S.-W. Rhee, Electrochem. Solid-State Lett., 1999, 2, 622-623.

140 J. Powell and B. L. Shaw, J. Chem. Soc. A, 1968, 159-161. 
141 D. Barreca, A. Buchberger, S. Diaolio, L. E. Depero, M. Fabrizio, F. Morandini, G. A. Rizzi, L. Sangaltti and E. Tondello, Langmuir, 1999, 15, 4537-4543.

142 S. Barison, D. Barreca, S. Daolio, M. Fabrizio and E. Tondello, J. Mater. Chem., 2002, 12, 1511-1518.

143 S. Barison, D. Barreca, S. Daolio, M. Fabrizio and C. Piccirillo, Rapid Commun. Mass Spectrom., 2000, 14, 1179-1183.

144 T. Ando, N. Nakata, K. Suzuki, T. Matsumotoa and S. Ogo, Dalton Trans., 2012, 41, 1678-1682.

145 P. M. S. Monk, R. J. Mortimer and D. R. Rosseinsky, Electrochromism: Fundamentals and Applications, $\mathrm{VCH}$, Weinheim, 1995.

146 Y.-H. Song, Y.-L. Chen, Y. Chi, C.-S. Liu, W.-L. Ching, J.-J. Kai, R.-S. Chen, Y.-S. Huang and A. J. Carty, Chem. Vap. Deposition, 2003, 9, 162-169.

147 C. R. Eady, B. F. G. Johnson and J. Lewis, J. Chem. Soc., Dalton Trans., 1975, 2606-2611.

148 H. Li, D. B. Farmer, R. G. Gordon, Y. Lin and J. Vlassak, J. Electrochem. Soc., 2007, 154(12), D642-D647.

149 H. Li, T. Aaltonen, Z. Li, B. S. Lim and R. G. Gordon, Open Inorg. Chem. J., 2008, 2, 11-17 and references there in.

150 H. L. Skriver and N. M. Rosengaard, Phys. Rev. B: Condens. Matter Mater. Phys., 1992, 46, 7157.
151 D. Bekermann, D. Barreca, A. Gasparotto and C. Maccato, CrystEngComm, 2012, 14, 6347-6358.

152 S. F. Huang, Y. Chi, C. S. Liu, A. J. Carty, K. Mast, C. Bock, B. MacDougall, S. M. Peng and G. H. Lee, Chem. Vap. Deposition, 2003, 9, 157-161.

153 J. Shin, A. Waheed, K. Agapiou, W. A. Winkenwerder, H.-W. Kim, R. A. Jones, G. S. Hwang and J. G. Ekerdt, J. Am. Chem. Soc., 2006, 128, 16510-16511.

154 J. Shin, A. Waheed, W. A. Winkenwerder, H.-W. Kim, K. Agapiou, R. A. Jones, G. S. Hwang and J. G. Ekerdt, Thin Solid Films, 2007, 515, 5298-5307.

155 W. J. McCarty, X. Yang, L. J. D. Anderson and R. A. Jones, Dalton Trans., 2012, 41, 13496-13503.

156 M. Sakata, T. Kimura and T. Goto, Mater. Trans., 2007, 48(1), 58-63.

157 C. Li, W. K. Leong and K. P. Loh, Appl. Organomet. Chem., 2009, 23, 196-199.

158 N. Popovska, K. Danova, I. Jipa and U. Zenneck, Powder Technol., 2011, 207, 17-25.

159 F. Z. Bouanis, L. Baraton, V. Huc, D. Pribat and C. S. Cojocaru, Thin Solid Films, 2011, 519, 4594-4597.

160 W. Liao and J. G. Ekerdt, Chem. Mater., 2013, 25, 17931799. 